NIST Special Publication 1031

\title{
Round Robin Study of Total Heat Flux Gauge Calibration at Fire Laboratories
}

\author{
William M. Pitts \\ Annageri V. Murthy \\ John L. de Ris \\ Jean-Rémy Filtz \\ Kjell Nygård \\ Debbie Smith \\ Ingrid Wetterlund
}




\section{Round Robin Study of Total Heat Flux Gauge Calibration at Fire Laboratories}

William M. Pitts
Building and Fire Research Laboratory

Annageri V. Murthy Aero-Tech, Inc. Hampton, VA 23666

John L. de Ris FM Global Research

Norwood, MA

Jean-Rémy Filtz LNE: French National Metrology and Testing Laboratory Trappes, France

Kjell Nygård SINTEF NBL Norwegian Fire Research Laboratory

Trondheim, Norway

Debbie Smith The Fire Division of BRE

Garston, UK

Ingrid Wetterlund SP Swedish National Testing and Research Institute Borås, Sweden

October 2004

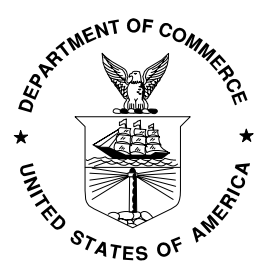

U.S. Department of Commerce Carlos M. Gutierrez, Secretary

Technology Administration Phillip J. Bond, Under Secretary for Technology

National Institute of Standards and Technology Hratch G. Semerjian, Acting Director 
Certain commercial entities, equipment, or materials may be identified in this document in order to describe an experimental procedure or concept adequately. Such identification is not intended to imply recommendation or endorsement by the National Institute of Standards and Technology, nor is it intended to imply that the entities, materials, or equipment are necessarily the best available for the purpose.

National Institute of Standards and Technology Special Publication 1031

Natl. Inst. Stand. Technol. Spec. Publ. 1031, 36 pages (October 2004) CODEN: NSPUE2

For sale by the Superintendent of Documents, U.S. Government Printing Office Internet: bookstore.gpo.gov — Phone: (202) 512-1800 — Fax: (202) 512-2250 Mail: Stop SSOP, Washington, DC 20402-0001 


\begin{abstract}
Total heat flux gauges are widely employed in fire research and fire testing laboratories. Several fire laboratories have developed systems for calibrating these gauges. There are major differences between these calibration facilities, and prior to this work there had been no systematic check of the degree of agreement between calibrations from the different laboratories. This report describes the results of two round robins in which five fire laboratories performed independent calibrations of two sets of Gardon and Schmidt-Boelter total heat flux gauges (i.e., a total of four gauges). One set of the gauges was also calibrated by two additional laboratories whose primary focus is measurement and calibration. Even though systematic variations between calibrations from the different laboratories were identified, the degree of agreement is viewed as being satisfactory for most fire testing and research purposes. Additional experimental findings concerning gauge angular response and linearity are presented. The need to develop a better understanding of the relative response of this type of gauge to radiative and convective heat transfer is emphasized.
\end{abstract}

Keywords: calibrating; convective heat transfer; Gardon gauges; heat flux; round robin; Schmidt-Boelter gauges; thermal radiation 


\section{TABLE OF CONTENTS}

Abstract.ape

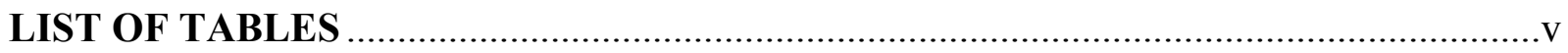

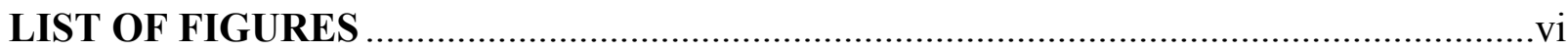

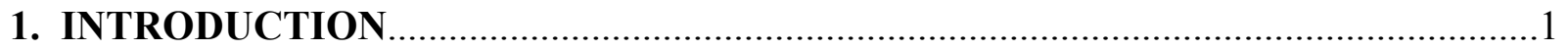

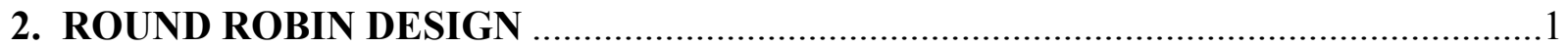

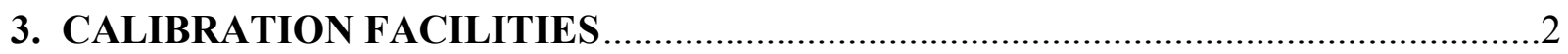

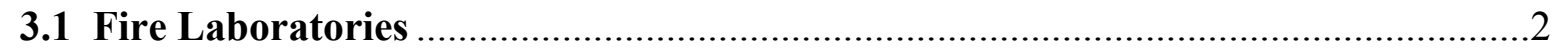



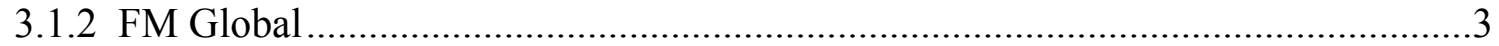

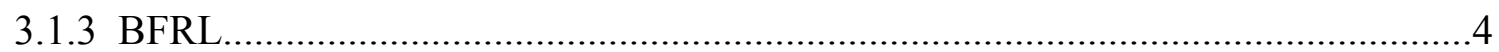

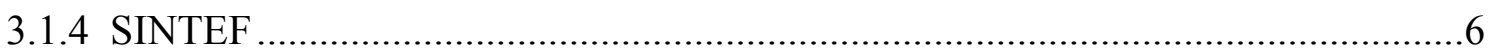

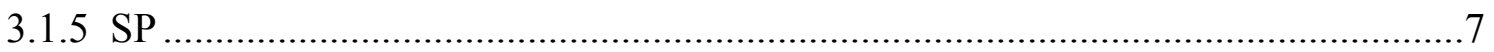

3.1.6 Summary of Fire Laboratory Calibration Facilities ..........................................

3.2 Measurement Laboratory Calibration Facilities ................................................ 10

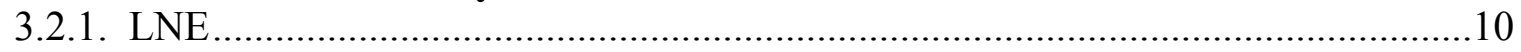

3.2.2. PL ......................................................................................................... 11

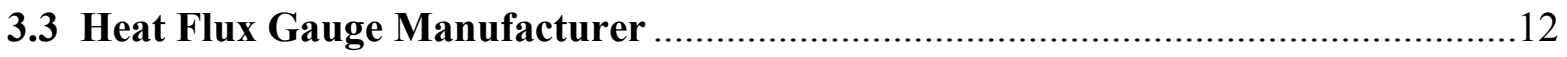

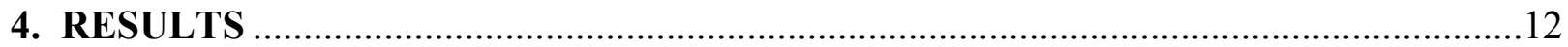

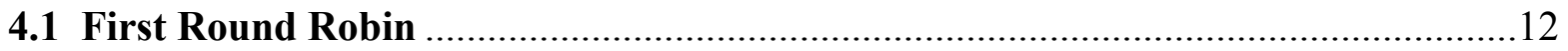

4.2 Calibrations of First Round Gauges by the Manufacturer, LNE, and PL .............15

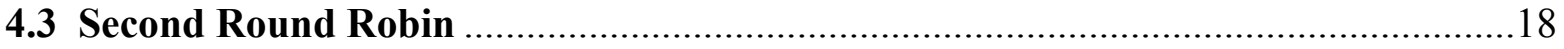

4.4 Comparisons Based on Predicted Full Scale Gauge Responses ...........................21

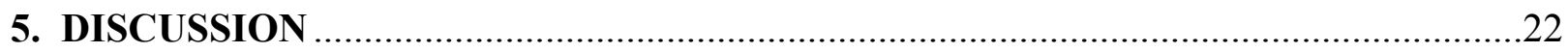

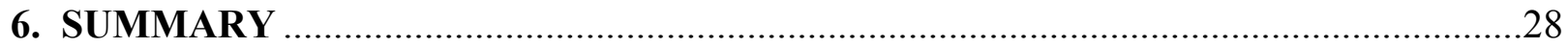

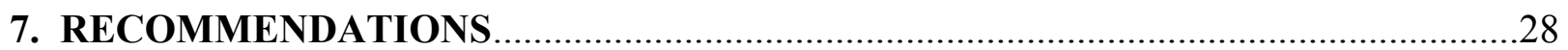

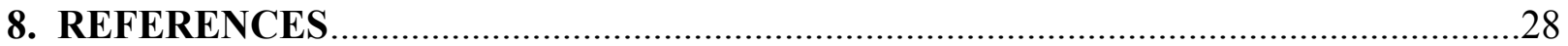




\section{LIST OF TABLES}

Table 1. Radiant Source, Method for Characterizing Heat Flux Level at Gauge, Source View Angle and Maximum Heat Flux at the Gauge for Fire Laboratory Calibration Methods

Table 2. Results of Linear Least Squares Curve Fits to Calibrations for the Schmidt-Boelter Gauge Used in the First Round Robin

Table 3. Results of Linear Least Squares Curve Fits to Repeated BFRL Calibrations of the Schmidt-Boelter Gauge Used in the First Round Robin

Table 4. Results of Linear Least Squares Curve Fits to Calibrations for the Gardon Gauge Used in the First Round Robin

Table 5. Results of Linear Least Squares Curve Fits to Repeated BFRL Calibrations of the Gardon Gauge Used in the First Round Robin

Table 6. Calibration Results from Two Measurement Laboratories and the Gauge Manufacturer for the Schmidt-Boelter Gauge Used in the First Round Robin

Table 7. Calibration Results from Two Measurement Laboratories and the Gauge Manufacturer for the Gardon Gauge Used in the First Round Robin

Table 8. Results of Linear Least Squares Curve Fits to Calibrations for the Schmidt-Boelter Gauge Used in the Second Round Robin

Table 9. Results of Linear Least Squares Curve Fits to Repeated BFRL Calibrations of the Second Schmidt-Boelter Gauge.

Table 10. Results of Linear Least Squares Curve Fits to Calibrations for the Gardon Gauge Used in the Second Round Robin

Table 11. Results of Linear Least Squares Curve Fits to Repeated BFRL Calibrations of the Second Gardon Gauge

Table 12. Manufacturer Calibrations Results for the Schmidt-Boelter and Gardon Gauges Used during the Second Round Robin 


\section{LIST OF FIGURES}

Figure 1. A schematic of the BRE/FRS apparatus for heat flux gauge

page calibration is shown. It consists of a gas-fired radiant panel as the heat source and specially designed equipment for holding and positioning either the calibrated reference gauge or the gauge to be tested.

Figure 2. A schematic for the FM Global calibration apparatus is shown......................4

Figure 3. View of the BFRL heat flux gauge calibration facility. From right to left the major components are the housing for the high pressure $2000 \mathrm{~W}$ tungsten-halogen filament lamp, flux redistributor, and gauge holder.

Figure 4. A picture from below and a schematic are shown of the spherical furnace used for heat flux gauge calibration by SINTEF.

Figure 5. A cross-sectional view of the calibration furnace (NT FIRE 050) used at SP for heat flux gauge calibration is shown.

Figure 6. A cross-sectional view of the LNE vacuum black body cavity (VBBC) used for heat flux gauge calibration is shown.

Figure 7. A schematic layout of the PL $25 \mathrm{~mm}$ Variable-Temperature Blackbody is shown.

Figure 8. Calibration results from the five participating fire laboratories for the Schmidt-Boelter total heat flux gauge used during the first round robin are plotted as heat flux versus gauge reading.

Figure 9. Results of repeated calibrations by BFRL of the two gauges used during the first round of the round robin are plotted as applied heat flux versus gauge reading. Symbols correspond to: $\bullet$ repeated calibrations at the start of the round robin, a results following calibrations by the fire laboratories, and $\Delta$ results following calibrations by the measurement laboratories.

Figure 10. Calibration results from the five participating laboratories for the Gardon total heat flux gauge used during the first round robin are plotted as heat flux versus gauge reading.

Figure 11. Calibration results by the gauge manufacturer, LNE, and PL for the Schmidt-Boelter total heat flux gauge used during the first round robin are plotted as heat flux versus gauge reading. The results for the five fire laboratories shown in Fig. 8 are included as dotted lines.

Figure 12. Calibration results by the gauge manufacturer, LNE, and PL for the Gardon total heat flux gauge used during the first round robin are plotted as heat flux versus gauge reading. The results for the five fire laboratories shown in Figure $\mathbf{1 0}$ are included as dotted lines.

Figure 13. Calibration results from the five participating laboratories for the Schmidt-Boelter total heat flux gauge used during the second round robin are plotted as heat flux versus gauge reading. The result for the gauge manufacturer is included for reference. 
Figure 14. Results of repeated calibrations by BFRL of the two gauges used during the second round robin are plotted as applied heat flux versus gauge reading. Symbols correspond to: • repeated calibrations at the start of the round robin and a calibration following calibrations by the fire laboratories.

Figure 15. Calibration results from the five participating laboratories for the Gardon total heat flux gauge used during the second round robin are plotted as heat flux versus gauge reading. The result for the gauge manufacturer is included for reference.

Figure 16. Calibration results for the five fire laboratories and two measurement laboratories are compared for the two gauges used during the first round robin by plotting the predicted full scale responses (i.e., the heat flux corresponding to a $10 \mathrm{mV}$ gauge output) versus the manufacturer's results (line). Uncertainties based on experimental results and determined as described in the text are indicated for the results from the fire laboratories.

Figure 17. Calibration results for the five fire laboratories are compared for the two gauges used during the second round robin by plotting the predicted full scale responses (i.e., the heat flux corresponding to a $10 \mathrm{mV}$ gauge output) versus the manufacturer's results (line).

Uncertainties based on experimental results and determined as described in the text are indicated.

Figure 18. The angular response recorded by FM Global for the SchmidtBoelter gauge used during the first round robin is shown in the top graph as normalized gauge response versus radiation angle. The data are replotted in the lower graph after dividing the normalized gauge response by the cosine of the incident angle $(\theta)$. The solid line is the result of a fit of the experimental data to the indicated form with $\varepsilon=\mathbf{0 . 0 1 8}$.

Figure 19. The angular response recorded by FM Global for the Gardon gauge used during the first round robin is shown in the top graph as normalized gauge response versus incidence angle. The data are replotted in the lower graph after dividing the normalized gauge response by the cosine of the incident angle $(\theta)$. The solid line is the result of a fit of the experimental data to the indicated form with $\varepsilon=0.025$.

Figure 20. Residuals derived from linear least squares curve fits to calibration results recorded by SP are plotted as a function of the gauge reading in millivolts for the $A$ ) first round Schmidt-Boelter gauge, B) first round Gardon gauge, $C$ ) second round SchmidtBoelter gauge, and $D$ ) second round Gardon gauge. 


\section{INTRODUCTION}

Many types of experimental measurements are important for fire science and engineering. In recent years there has been an increased emphasis on improving the quality of these measurements and the need to quantify their uncertainties. In 2000 the Building and Fire Research Laboratory (BFRL) at the National Institute of Standards and Technology (NIST) hosted a workshop on this topic entitled "Measurement Needs for Fire Safety: An International Workshop" at the request of the FORUM for International Cooperation in Fire Research. [1] One of the recommendations generated by the workshop participants was that a collaborative effort among the member laboratories should focus on characterizing the uncertainties associated with heat flux measurement in fire environments.

As a result of this meeting the FORUM Heat Flux Measurement Working Group was formed in July, 2000. During initial discussions it was discovered that a variety of different approaches were being employed in the laboratories to calibrate heat flux gauges. Schmidt-Boelter and Gardon gauges were typically used for total heat flux measurements. To the knowledge of the participants, the various calibration approaches had not been directly compared previously, and it was decided to conduct a calibration round robin in order to assess the consistency of the different approaches. Ultimately two independent round robins using Schmidt-Boelter and Gardon gauges were completed with five fire laboratories participating. Additionally, the four gauges were calibrated by the manufacturer, and the two gauges used during the first round robin were calibrated by two additional calibration laboratories, LNE in France and the Physics Laboratory (PL) at NIST.

The need for improved calibration facilities and procedures has been generally recognized in a variety of engineering fields requiring accurate heat flux measurement. A workshop held at NIST in 1999 summarized the needs of several industries, along with those of fire science. [2] The workshop proceedings include a summary of an effort within the International Standards Organization aimed at standardizing heat flux gauge calibrations for use in fire science and engineering studies. Much of the work supporting the development of this new standard has been performed as part of a European cooperative project known as HFCAL. Even though some laboratories have participated in both the HFCAL study and the current round robin, the investigations have been performed independently.

\section{ROUND ROBIN DESIGN}

The fire laboratories participating in the round robin were BRE/FRS, FM Global, BFRL, SINTEF, and SP. The heat flux gauge calibration facilities utilized by the participating laboratories differ substantially from one another. An approach was adopted in which each fire laboratory carried out calibrations using their existing method following standard internal procedures.

The pattern (nomenclature utilized here is taken from the Guide for Interlaboratory Comparisons [3]) was the "basic circular" in which these gauges were first calibrated by a "pivot" laboratory, in this case BFRL, and then sent sequentially to the other participating 
laboratories. At the completion of the circle the gauges were returned to BFRL for recalibration to check that travel and handling had not measurably altered the responses of the two gauges.

Two commercial heat flux gauges from Medtherm Corporation ${ }^{1}$, a $2.54 \mathrm{~cm}$ Gardon gauge (Model 64-10-18ST) and a $1.27 \mathrm{~cm}$ Schmidt-Boelter gauge (Model 32-10SB-18ST), procured by BFRL were calibrated by the five laboratories during each of two round robins. Since new gauges were employed for each round robin, a total of four gauges were tested. The nominal full-scale ranges for the gauges were $100 \mathrm{~kW} / \mathrm{m}^{2}$. Calibrations for each gauge were made by the manufacturer prior to delivery, but were not disclosed to BFRL until the completion of a round robin. The gauges were shipped between the laboratories in a foam-rubber-lined case.

At the conclusion of the first round robin the two gauges were sent to the two calibration laboratories, LNE and PL, for additional calibrations. Following each of these calibrations BFRL again checked the gauges for calibration changes.

Three of the laboratories, LNE, SP, and PL, that calibrated the first set of gauges used approaches that are mentioned as primary calibration methods in part 2 of the proposed ISO standard that is currently under development. [4] One of the fire laboratories, BRE/FRS, used a method mentioned as a secondary calibration method in part 3 of the ISO standard under development. [5] The approaches used for the three remaining fire laboratories are not mentioned in the ISO documents.

\section{CALIBRATION FACILITIES}

\subsection{Fire Laboratories}

\subsubsection{BRE/FRS}

The calibration of heat flux gauges for use as working standards is carried out by comparing their response at various levels of irradiance with the response of a secondary standard gauge at the same levels of irradiance. The measurements are made at multiple heat flux levels by varying the distance between the radiant source and the gauges.

The radiant source is a $0.3 \mathrm{~m}$ by $0.3 \mathrm{~m}$ porous refractory burner operating on pre-mixed natural gas with air. It is mounted vertically and is operated in the temperature range of $800{ }^{\circ} \mathrm{C}$ to $1000{ }^{\circ} \mathrm{C}$.

Both the secondary standard heat flux gauge and the instrument to be calibrated are mounted side-by-side on a sliding frame and moved into the measuring position, opposite the center of the radiant source, in turn. The output from the measuring gauge is recorded until it has stabilized. The average value of the output is then determined over a one minute period. The two gauges are moved into the measuring position alternately until two corresponding averages for the secondary standard gauge and the instrument to be calibrated do not differ by more than $1 \%$.

\footnotetext{
${ }^{1}$ Certain commercial equipment, instruments, or materials are identified in this paper in order to adequately specify the experimental procedure. Such identification does not imply recommendation or endorsement by the National Institute of Standards and Technology, nor does it imply the materials or equipment are necessarily the best available for the purpose.
} 
The incident irradiance on the gauges is increased by moving them closer to the radiant source. The upper limit of irradiance within this facility is $55 \mathrm{~kW} / \mathrm{m}^{2}$. Beyond this limit, the gauges are susceptible to significant convective effects. A schematic diagram of the apparatus is shown in Fig. 1. Maximum heat flux values used in the current calibrations were close to the maximum available, ranging from $52 \mathrm{~kW} / \mathrm{m}^{2}$ to $56 \mathrm{~kW} / \mathrm{m}^{2}$.

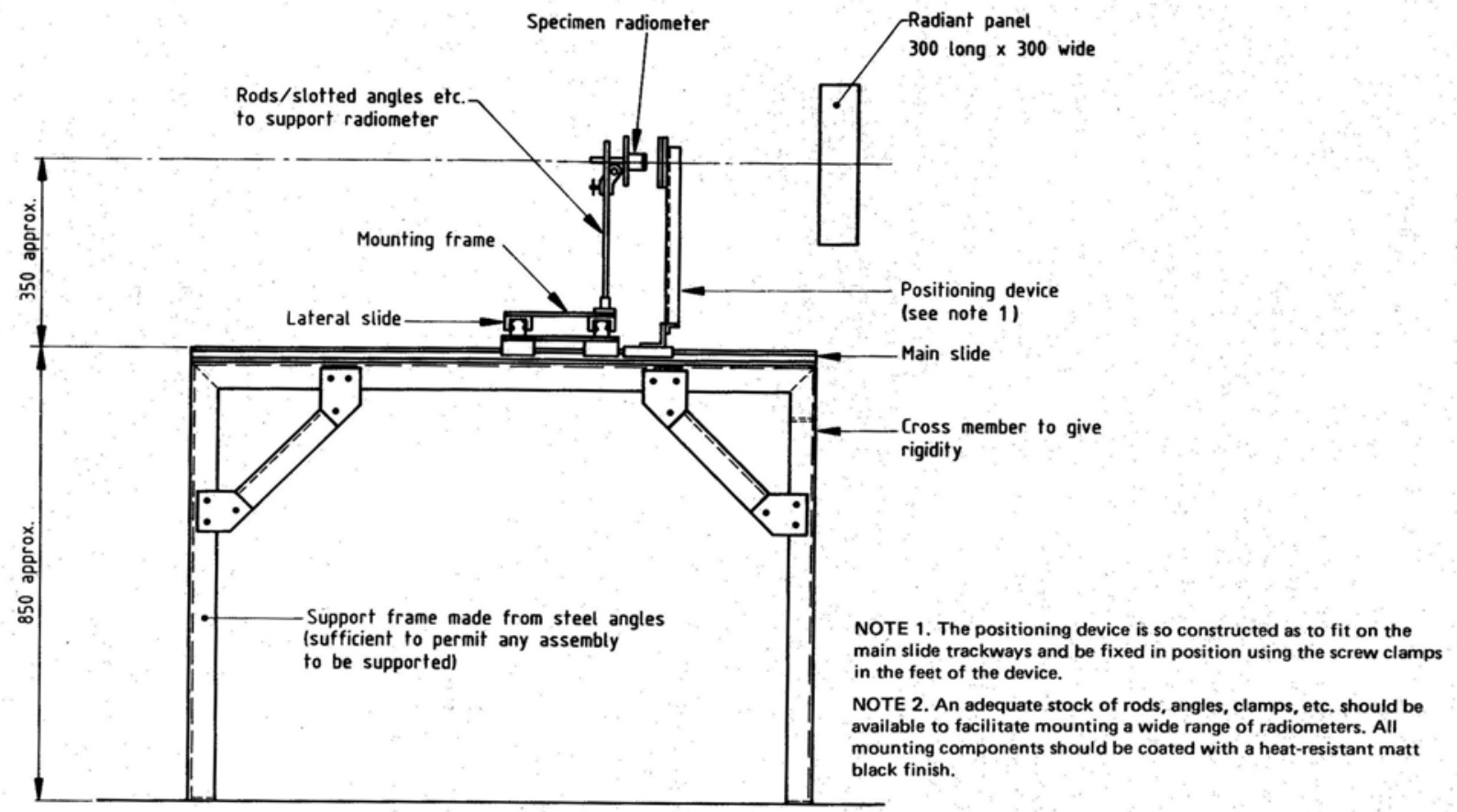

Figure 1. A schematic of the BRE/FRS apparatus for heat flux gauge calibration is shown. It consists of a gas-fired radiant panel as the heat source and specially designed equipment for holding and positioning either the calibrated reference gauge or the gauge to be tested.

The calibration apparatus is located within a small room to ensure that the environment is draught free.

The secondary radiometer was calibrated by LNE.

\subsubsection{FM Global}

For the past thirty years, FM Global has calibrated its gauges by placing them at several different distances in front of a hot furnace orifice that emits a known level of radiance. It is a primary method of calibration based on first principles (e.g. the Stefan-Boltzmann constant) rather than being based on a transfer calibration from some other device.

Figure 2 illustrates the method of calibration. The facility includes a furnace (F) with a conical blackbody target (T) emitting a known quantity of blackbody radiant heat flux. The furnace is designed to maximize the effective emissivity of the target. Radiation exits the furnace through a 


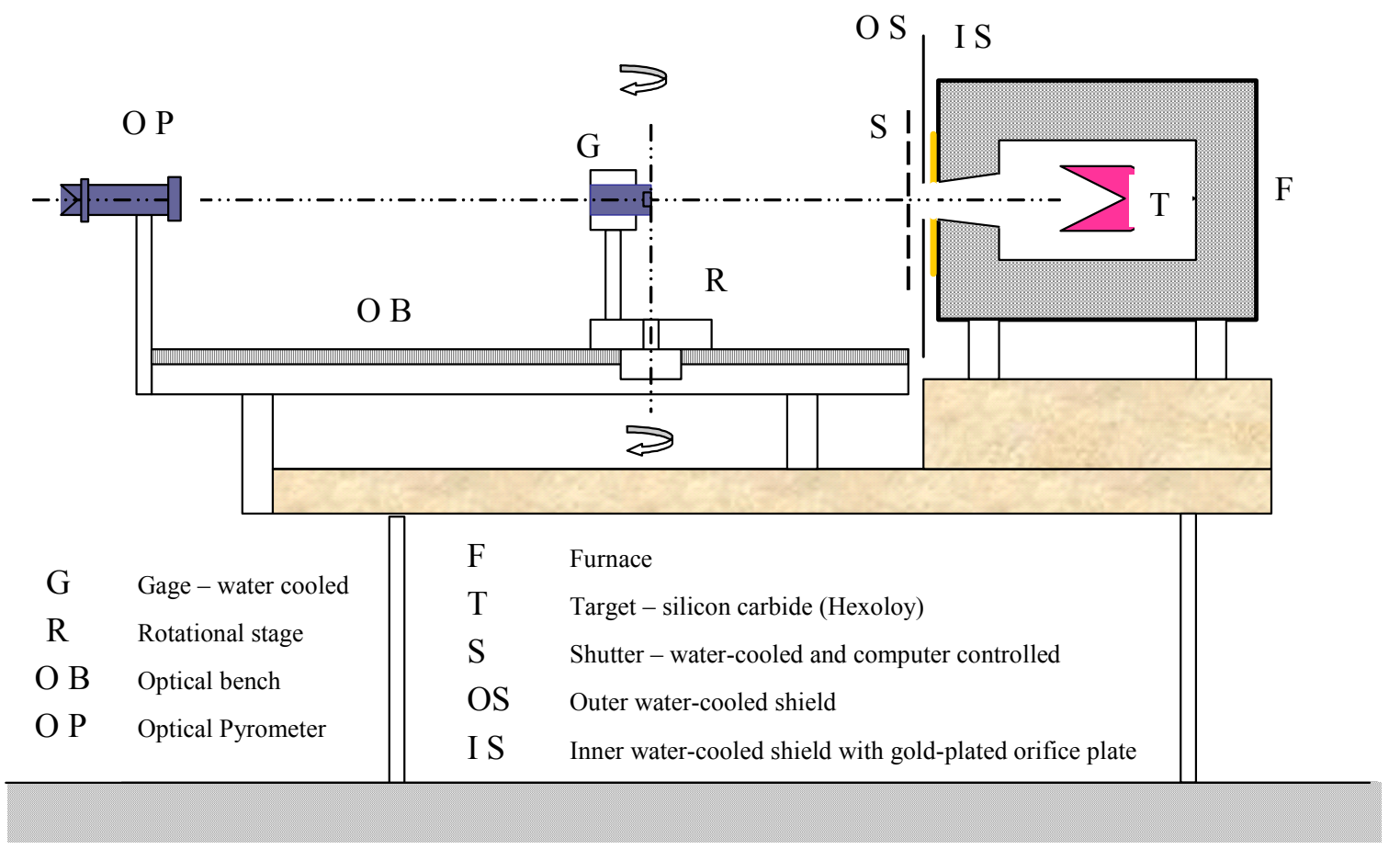

Figure 2. A schematic for the FM Global calibration apparatus is shown.

water-cooled gold-plated orifice (IS) followed by a much larger water-cooled outer shield (OS). The target temperature is measured by the optical pyrometer (OP). Measurement precision is greatly enhanced through the use of a computer-controlled water-cooled shutter (S) and black shielding surrounding the furnace orifice. The shutter periodically blocks radiation from the orifice to avoid the effect of stray radiation not coming from the orifice. The gauge $(\mathrm{G})$, being calibrated, is mounted on a rotational stage $(\mathrm{R})$ and optical bench $(\mathrm{OB})$. The carriage is precisely positioned at various distances from the orifice using Invar rods. The gauge, shutter, and shielding are all water cooled at the temperature of the ambient air to minimize effects of stray radiation, convective heat transport and air drafts. Calibrations are generally reproducible to $\pm 0.5 \%$ and accurate to $\pm 1 \%$.

This facility measures the gauge sensitivity to both normally incident flux and to flux incident at oblique angles. This is a significant advantage. Gauges often have unexpected angular dependencies that one must take into consideration. A drawback of calibrating gauges outside the furnace is that heat fluxes incident on the gauge are two orders of magnitude less than the $100 \mathrm{~kW} / \mathrm{m}^{2}$ fluxes that can be measured in fires. One must rely on the gauges having a linear response. Maximum applied heat fluxes for the gauges used in the current round robins were close to or just less than $1.0 \mathrm{~kW} / \mathrm{m}^{2}$.

\subsubsection{BFRL}

The BFRL heat flux gauge calibration system was assembled in the mid 1970s. It has been described in a recent NIST Report of Test. [6]. It is based on comparing the response of the gauge to be calibrated with that for a calibrated secondary standard gauge for a range of applied heat fluxes. 
The heat source consists of a commercial radiant heater incorporating a $2000 \mathrm{~W}$ tungstenhalogen filament lamp. The lamp is placed at one of the foci of a large ellipsoidal reflector, with the entrance to a kaleidoscope flux redistributor being located at the other. The distance between the foci is $30.5 \mathrm{~cm}$. A metal housing surrounds the half of the ellipsoidal mirror containing the lamp. The mirror passes through the wall of the housing and extends $10 \mathrm{~cm}$ before being cut off short of the second focus of the ellipse. The lamp housing with extended mirror can be seen in the photograph shown in Fig. 3.

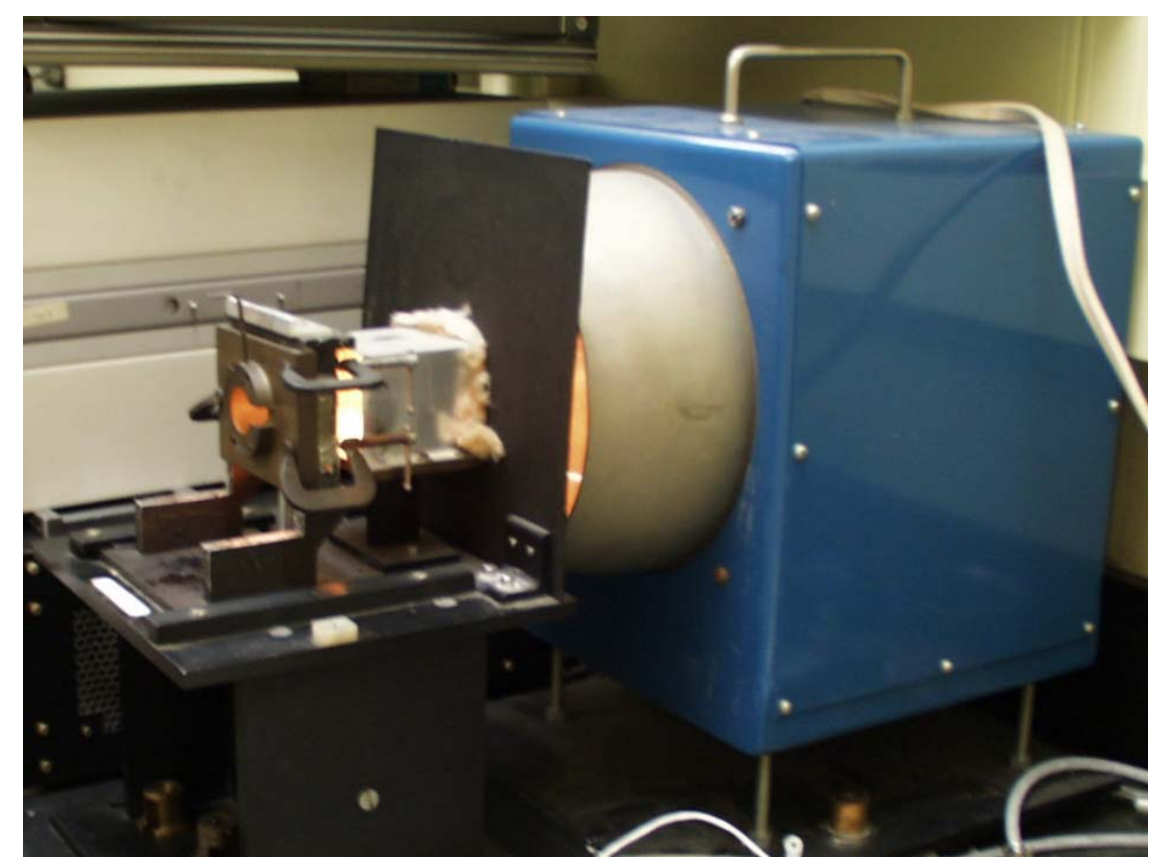

Figure 3. View of the BFRL heat flux gauge calibration facility. From right to left the major components are the housing for the high pressure $2000 \mathrm{~W}$ tungstenhalogen filament lamp, flux redistributor, and gauge holder.

A blackened radiation shield with a $6.4 \mathrm{~cm}$ square cut out centered on the mirror axis is positioned $2.5 \mathrm{~cm}$ from the lamp. A $7.6 \mathrm{~cm}$ long box, open at both ends, is attached over the radiation shield cut out on the opposite side of the lamp. (see Fig. 3) The interior of the box provides internal reflections of light that redistribute the energy flux by forming and superimposing multiple images such that the flux distribution becomes more uniform at the exit, similar to the multiple images formed by a kaleidoscope. The gauge to be characterized is positioned at a reproducible location on the far side of the kaleidoscope flux redistributor using a specially designed mount.

Heat flux calibrations are performed using a secondary-standard heat flux gauge that was calibrated by the Radiometric Physics Division of the National Bureau of Standards (now NIST). An arbitrary heat flux level is set by adjusting the lamp power supply voltage and current, and the lamp is allowed to stabilize (20 min). After stabilization the output $(\mathrm{mV})$ of the secondarystandard heat flux gauge is recorded. The secondary standard is then replaced with the gauge to be tested, and the output is again recorded. Once a calibration cycle is complete, the lamp output is adjusted to the next flux level, and the measurement procedure is repeated. Generally, four 
flux levels over a $0 \mathrm{kw} / \mathrm{m}^{2}$ to $15 \mathrm{~kW} / \mathrm{m}^{2}$ range are chosen. For the current round robins, maximum applied heat fluxes for a given calibration ranged from $15.8 \mathrm{~kW} / \mathrm{m}^{2}$ to $16.6 \mathrm{~kW} / \mathrm{m}^{2}$. Following the completion of a calibration, the results are plotted as incident heat flux $\left(\mathrm{kW} / \mathrm{m}^{2}\right)$ versus the corresponding gauge output readings in $\mathrm{mV}$. The experimental data are fit using a linear least squares procedure, and the gauge sensitivity is reported in terms of $\left(\mathrm{kW} / \mathrm{m}^{2}\right) / \mathrm{mV}$.

\subsubsection{SINTEF}

Calibrations of heat flux gauges are performed at SINTEF using a MIKRON300 spherical furnace (Fig. 4) with a small opening at the bottom. The furnace is considered to be a primary black body radiation standard. The radiative flux impinging on the sphere's inner opening is obtained from the interior furnace surface temperature and the Stefan-Boltzman equation. Temperature variations along the cavity surface are estimated to be less than $1{ }^{\circ} \mathrm{C}$. The radiative flux is considered uniform for the full $180^{\circ}$ view available at the inside of the opening. Radiative heat flux levels can be varied from $0 \mathrm{~kW} / \mathrm{m}^{2}$ to $200 \mathrm{~kW} / \mathrm{m}^{2}$ by adjusting the temperature up to $1100{ }^{\circ} \mathrm{C}$. Maximum heat fluxes applied for the current calibrations were 98 $\mathrm{kW} / \mathrm{m}^{2}$ and $59 \mathrm{~kW} / \mathrm{m}^{2}$ for the first- and second-round gauges, respectively.
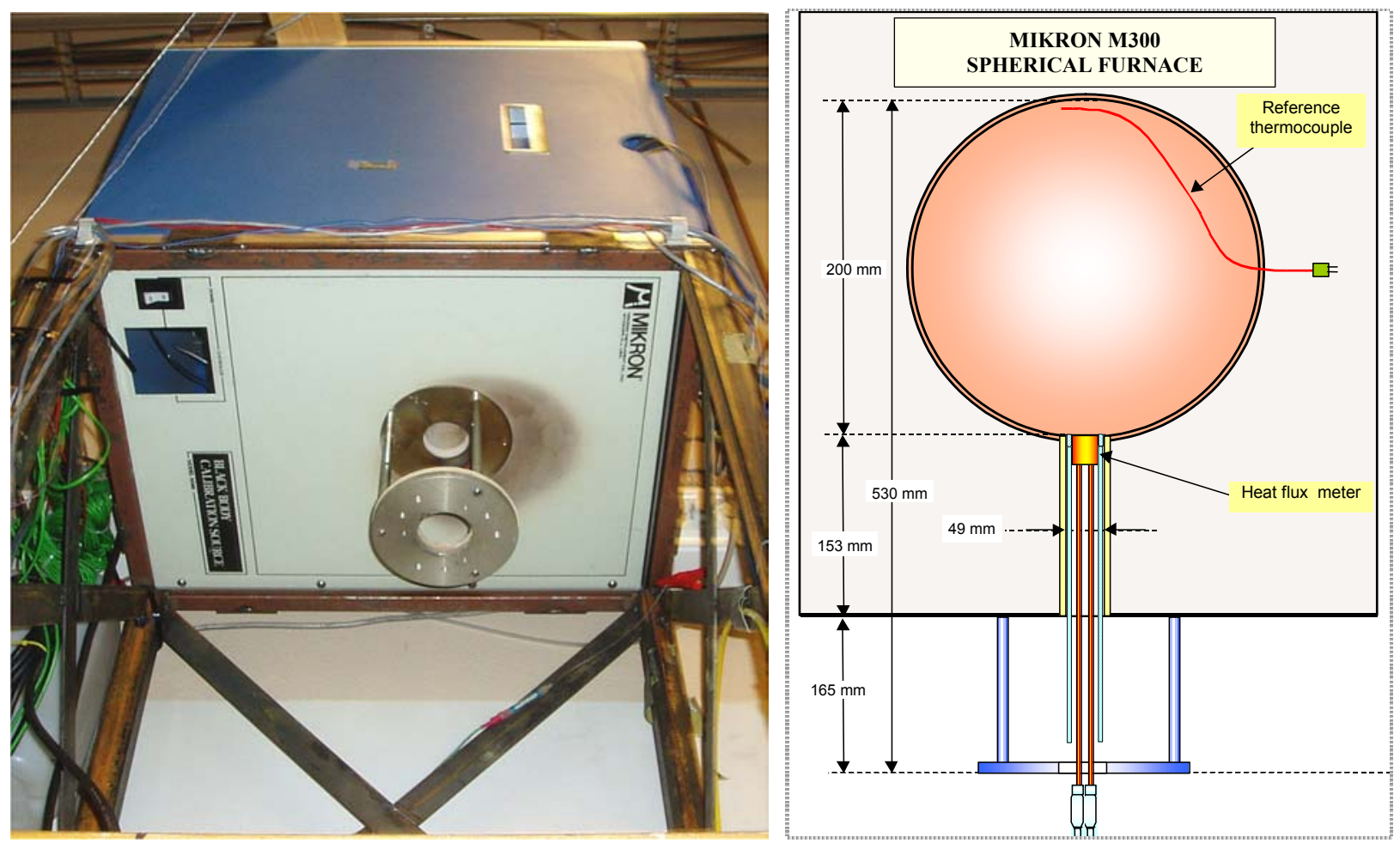

Figure 4. A picture from below and a schematic are shown of the spherical furnace used for heat flux gauge calibration by SINTEF.

The interior surface temperature of the furnace is recorded using a calibrated thermocouple with an output traceable to ITS-90 [7]. Typical uncertainties are $\pm 2{ }^{\circ} \mathrm{C}$. Various types of uncertainty are considered for the temperature measurement including thermocouple aging, various measurement uncertainties, effects of possible cold air draughts on the thermocouple, and view 
effects associated with the spherical cavity opening. The uncertainty in temperature measurement is estimated to result in an uncertainty of less than $1.7 \%$ in the opening radiative heat flux over the range $50 \mathrm{~kW} / \mathrm{m}^{2}$ to $100 \mathrm{~kW} / \mathrm{m}^{2}$.

Differences in temperature between the heated air inside the furnace and the room-temperature air outside can lead to the formation of air currents in the opening. As a result of these air flows, there is the potential for convective heat transfer to the gauge. Since Schmidt-Boelter and Gardon gauges are total heat flux gauges, they respond to convective heat transfer at their measuring surfaces. Additional uncertainties in the calibration are introduced due to convection. The convective contribution is dependent on the type of heat flux gauge, furnace temperature and the properties of the gas inside the furnace. Since the radiative heat flux increases faster than convection with temperature, the relative convective contribution decreases at higher flux levels. This means that calibrations at high heat flux levels have less relative uncertainty than at low levels.

If a reference total heat flux gauge with a well characterized response (i.e., low uncertainty) is available, the convective heat transfer component can be obtained by inserting the gauge flush with the furnace inner opening and measuring its response for each furnace temperature and using its known sensitivity to determine the total heat flux, $E_{\text {total }}$. The convective heat flux

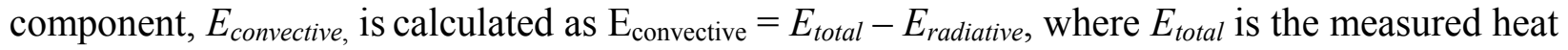
flux and $E_{\text {radiative }}$ is determined from the known black body temperature. The response of the heat flux gauge to be calibrated is also recorded for the same conditions, and its output is compared to the reference. Provided that the two heat flux meters have similar convective characteristics, the convective contribution to the heat flux can be determined for the gauge being calibrated. The uncertainty in the calibration of the reference heat flux gauge is quantified and added to the total uncertainty.

If a reference flux meter with sufficiently low uncertainty is not available, it is necessary to estimate/calculate the convective component and add this to the radiative heat flux in order to calculate $E_{\text {total }}$ for each furnace setting. The response of the heat flux gauge to be calibrated is then measured at each level, and the appropriate amount of convective heat transfer is added to the known radiative component. The uncertainty of the convective contribution has to be quantified and added to the total uncertainty.

The temperature of cooling water representing the temperature of the heat flux gauge body is also measured in order to allow the net heat flux to the gauge to be determined.

\subsubsection{SP}

The calibrations were performed according to NT FIRE $050[8,9,10]$, which is a primary calibration method. The method has been mainly used for calibration of total heat flux gauges of the Gardon and Schmidt-Boelter types. The system enables calibration from $2 \mathrm{~kW} / \mathrm{m}^{2}$ to $85 \mathrm{~kW} / \mathrm{m}^{2}$. For the current calibrations maximum applied heat fluxes were $85 \mathrm{~kW} / \mathrm{m}^{2}$ and $80 \mathrm{~kW} / \mathrm{m}^{2}$ for the Schmidt-Boelter and Gardon gauges used in the first round, respectively, and $76 \mathrm{~kW} / \mathrm{m}^{2}$, and $69 \mathrm{~kW} / \mathrm{m}^{2}$ for the gauges used in the second round. Heat flux gauges with a 
housing diameter of up to $50 \mathrm{~mm}$ and a sensitive area diameter of up to $10 \mathrm{~mm}$ can be accommodated.

The method consists of a blackbody radiation source designed as a well insulated, electrically heated spherical furnace chamber with an aperture at the bottom as shown in Fig. 5. The temperature of the furnace is accurately controlled and is quite uniform on the inside cavity surface, assuring a high precision for the radiation level. The method has an uncertainty equal to or less than $\pm 3.0 \%$ with a $95 \%$ confidence interval.

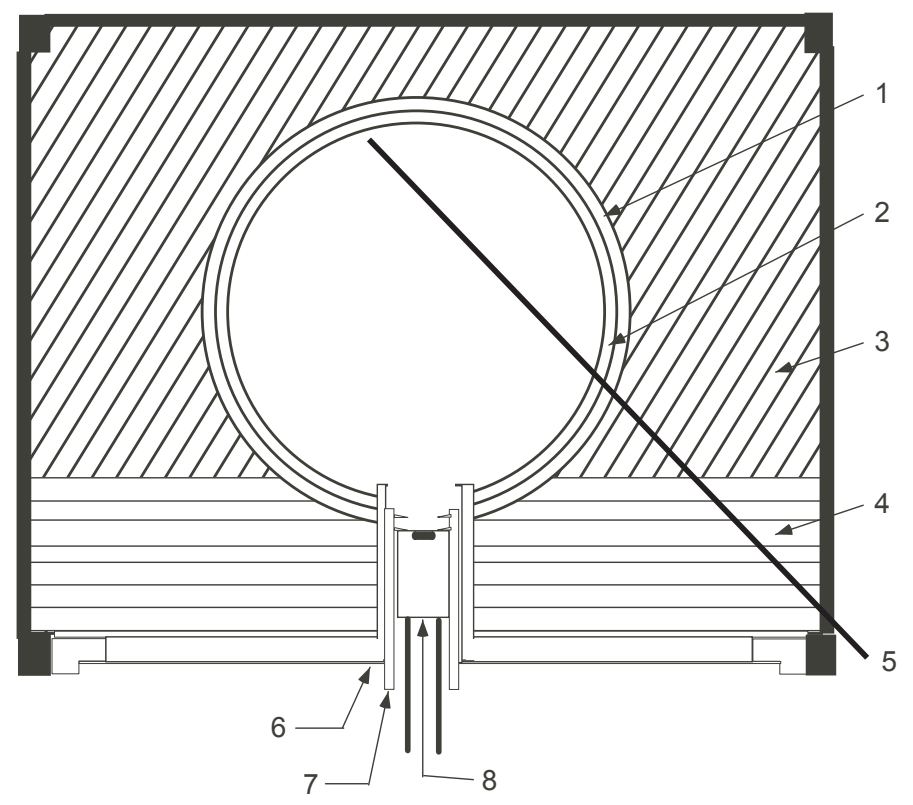

Key

1 Electric heater

$5 \quad$ Thermocouple

2 Ceramic clay

$6 \quad$ Fixed part of cooler

3 Low density ceramic insulation

$7 \quad$ Movable part of cooler

$4 \quad$ High density ceramic insulation

8 Heat flux gauge

Figure 5. A cross-sectional view of the calibration furnace (NT FIRE 050) used at SP for heat flux gauge calibration is shown.

A cooling device housing the heat flux gauge is inserted in the opening at the bottom of the furnace. The inside diameter of the furnace is larger than 4.5 times the restricting aperture of the fixed cooler at the bottom of the furnace. The aperture in the cooling device defines the view factor between the furnace radiating surface and the heat flux gauge.

Heat flux gauges to be calibrated are inserted through the aperture with the sensing surface oriented horizontally. The cooler has the same temperature as the heat flux gauge. The influence of convection is thus highly reduced. The cooler insert has a number of shields, which protect the gauge from receiving radiation reflected from the walls of the cooler. The shields help to maintain the stratification of air so that convective airflow is minimized. The heat flux gauge views only the controlled environment of the blackbody emitter and the much cooler 
surfaces of the cooler insert. The radiation level of this blackbody emitter depends solely on the measured temperature, making it traceable to international temperature calibration standards.

The calibration is performed at 10 flux levels, evenly distributed over a temperature range from $400{ }^{\circ} \mathrm{C}$ to a temperature corresponding to the maximum flux level of the gauge. The size of the sensing element for the gauge is required to calculate the view factor for the gauge. The manufacturer supplies this information. The distance between the top of the movable cooler and the receiving sensor of the heat flux gauge is also measured for this purpose. When the temperature of the black body has stabilized to within $\pm 1{ }^{\circ} \mathrm{C} / \mathrm{min}$ of the set level, records of the water and the furnace temperature together with the output signal from the gauge are taken over a 1 minute period (approximately 120 records). [10]

\subsubsection{Summary of Fire Laboratory Calibration Facilities}

Table 1 summarizes major characteristics for the calibration systems used by the participating fire laboratories. The type of heat source is indicated along with a general description of the approach used for estimating the heat fluxes impinging on the gauge to be calibrated and whether the gauge view of the heat source is limited to restrained angles near the gauge normal (narrow angle) or fills the entire field-of-view of the gauge (hemispherical). The last column lists nominal values of maximum heat flux that the various systems can impose on a heat flux gauge.

Table 1. Radiant Source, Method for Characterizing Heat Flux Level at Gauge, Source View Angle and Maximum Heat Flux at the Gauge for Fire Laboratory Calibration Methods

\begin{tabular}{|c|c|c|c|c|}
\hline $\begin{array}{c}\text { Fire } \\
\text { Laboratory }\end{array}$ & Source & Characterization & Angle & $\begin{array}{l}\text { Maximum } \\
\text { Applied HF }\end{array}$ \\
\hline BRE/FRS & Porous Burner & $\begin{array}{l}\text { Secondary } \\
\text { Standard }\end{array}$ & Narrow Angle & $55 \mathrm{~kW} / \mathrm{m}^{2}$ \\
\hline FM Global & $\begin{array}{c}\text { Target in } \\
\text { Cylindrical } \\
\text { Black Body }\end{array}$ & $\begin{array}{c}\text { Optical } \\
\text { Pyrometry }\end{array}$ & Narrow Angle & $1 \mathrm{~kW} / \mathrm{m}^{2}$ \\
\hline BFRL & $\begin{array}{c}\text { Tungsten Lamp } \\
\text { in Ellipsoidal } \\
\text { Furnace }\end{array}$ & $\begin{array}{l}\text { Secondary } \\
\text { Standard }\end{array}$ & Narrow Angle & $15 \mathrm{~kW} / \mathrm{m}^{2}$ \\
\hline SINTEF & $\begin{array}{c}\text { Spherical Black } \\
\text { Body }\end{array}$ & $\begin{array}{l}\text { Calibrated } \\
\text { Thermocouple }\end{array}$ & Hemispherical & $200 \mathrm{~kW} / \mathrm{m}^{2}$ \\
\hline SP & $\begin{array}{c}\text { Spherical Black } \\
\text { Body }\end{array}$ & $\begin{array}{c}\text { Calibrated } \\
\text { Thermocouple }\end{array}$ & Narrow Angle & $85 \mathrm{~kW} / \mathrm{m}^{2}$ \\
\hline
\end{tabular}




\subsection{Measurement Laboratory Calibration Facilities}

\subsubsection{LNE}

The LNE facility utilizes a traceable black body source, operated under vacuum in order to minimize convection, to irradiate the gauge to be calibrated. The Vacuum Black Body Cavity (VBBC) can reach irradiance levels up to $100 \mathrm{~kW} / \mathrm{m}^{2}$. However, due to the limited resistance of heat flux gauges in hot and low-pressure environments, the approach enables heat flux gauge calibration up to about $60 \mathrm{~kW} / \mathrm{m}^{2}$. The method consists of measuring the output voltage of the heat flux gauge for known flux levels. The absolute pressure in the blackbody cavity is maintained below $5 \mathrm{~Pa}$. In that case, the convective heat transfer is consequently reduced and accounted for with lower uncertainty. Radiation levels and residual convection are determined through modelling.

The apparatus (Fig. 6) consists of two essential parts: the gun, which is a cylindrical tube fixed on a carriage including the black body cavity, the heat flux gauge and its cooling pipes and the furnace, containing a set of heating resistors. Four regulators, whose thermocouples are localized close to each heater, control the heating of the cavity. The temperature range of the black body cavity is $23{ }^{\circ} \mathrm{C}$ to $900{ }^{\circ} \mathrm{C}$.

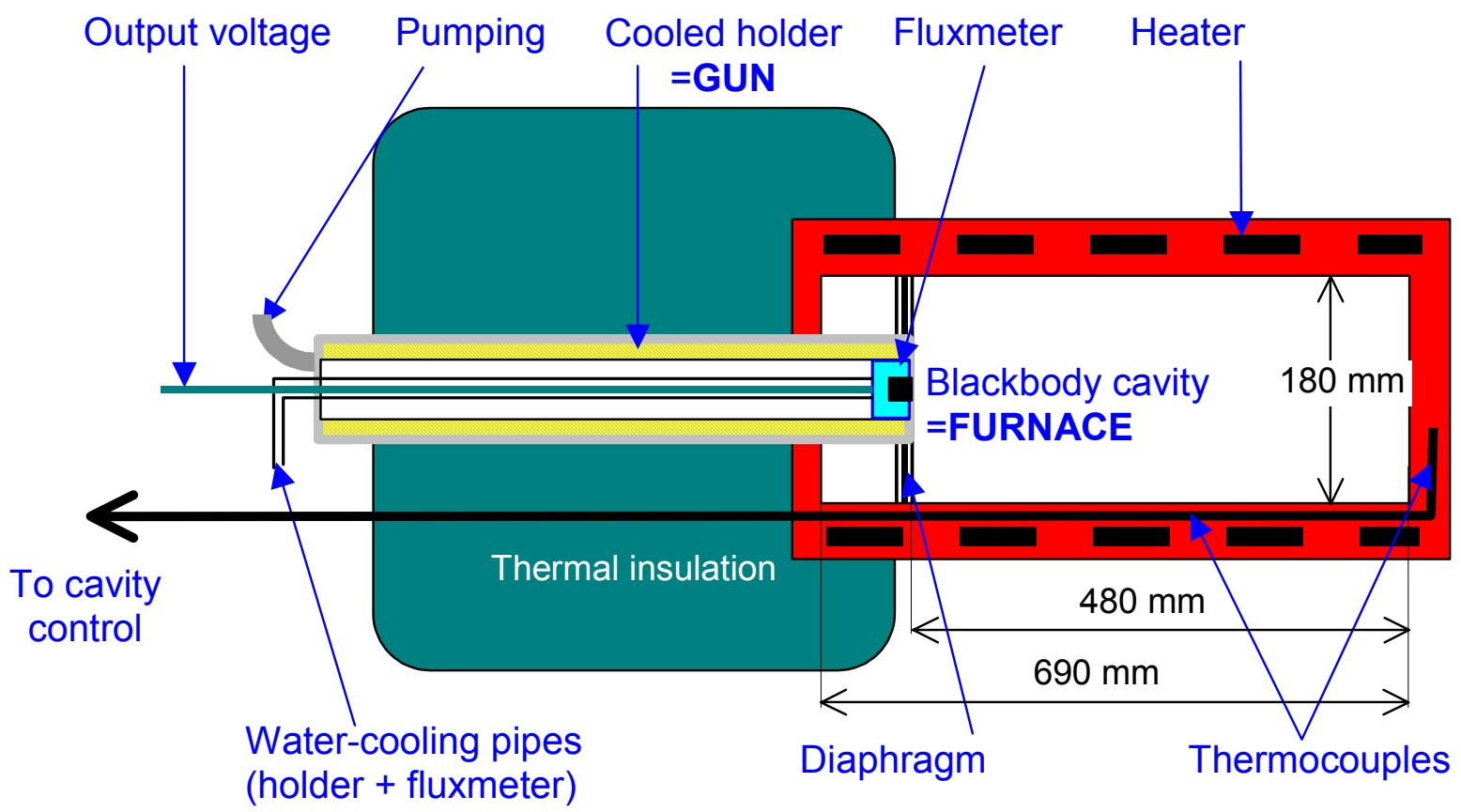

Figure 6. A cross-sectional view of the LNE vacuum black body cavity (VBBC) used for heat flux gauge calibration is shown.

Pressure measurement within the cavity is performed by means of a Pirani gauge. A set of thermocouples is mounted partly along and partly in the rear section of the black body cavity, allowing a determination of the temperature field. 
The calibration procedure consists of the following steps: 1) stabilizing the cavity at the requested temperature, 2) placing the heat flux gauge into the cavity so that its sensitive aperture is in the correct plane, 3) after 1 hour, pumping the cavity down to $1 \mathrm{~Pa}$, and 4) recording the heat flux gauge voltage for $300 \mathrm{~s}$ (30 values). The recorded quantities for each heat flux level are the computed total flux and the heat flux gauge output voltage, both with their standard deviations. The VBBC records also include the actual pressure, the residual relative convective flux and the overall uncertainty.

\subsection{2. $\mathrm{PL}$}

The PL technique uses the principle of electrical substitution radiometry to calibrate heat flux gauges up to $50 \mathrm{~kW} / \mathrm{m}^{2}$. The reference standard is a room-temperature electrical substitution radiometer whose calibration is traceable to the High Accuracy Cryogenic Radiometer (HACR), the United States primary standard for optical radiation power, through a chain of calibrations.

The calibration uses the $25 \mathrm{~mm}$ diameter dual cavity variable temperature blackbody (VTBB) as a broadband radiant source. Figure 7 shows a schematic layout of the VTBB apparatus and the calibration scheme. The direct resistance heating of the graphite tube element using large AC currents at low voltages allows quick heating and cooling of the cavity. An optical pyrometer measures the VTBB temperature by sensing radiation from one end of the cavity. A PID controller regulates the power supply to maintain the cavity temperature to within $\pm 0.1 \mathrm{~K}$ of the set value. The maximum operating temperature is $2973 \mathrm{~K}$.

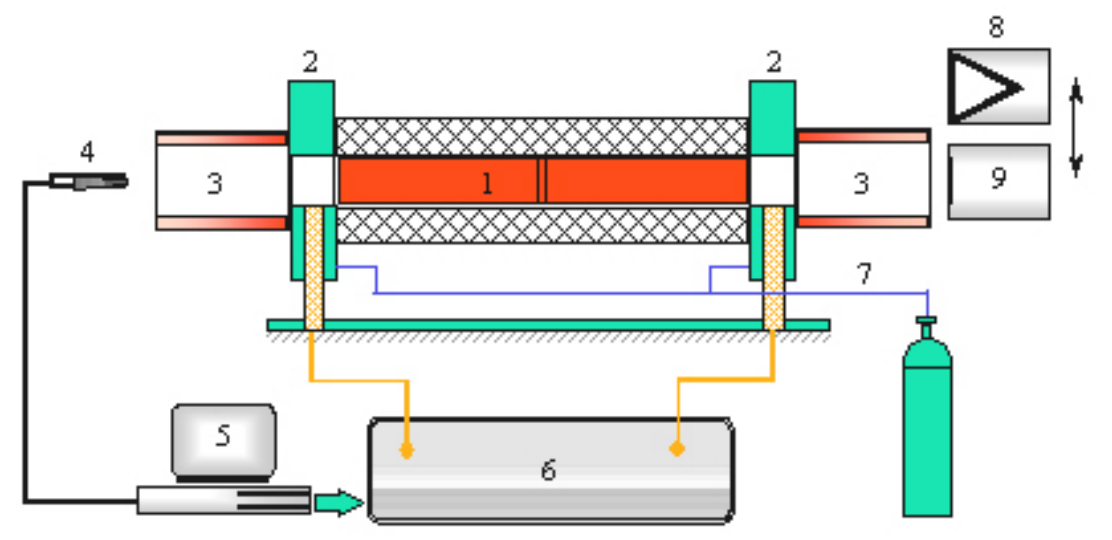

Key:
\begin{tabular}{|c|c|c|c|}
\hline 1 & Heated graphite tube dual-cavity & 6 & Power supply \\
\hline 2 & Water-cooled copper end caps & 7 & Purge gas lines (argon) \\
\hline 3 & Graphite tube extension (not cooled) & 8 & Transfer standard radiometer \\
\hline 4 & Control pyrometer & 9 & Test heat flux gauge \\
\hline 5 & Temperature controller/computer & & \\
\hline
\end{tabular}

Figure 7. A schematic layout of the PL $25 \mathrm{~mm}$ Variable-Temperature Blackbody is shown.

The reference standard radiometer is water cooled and is suitable for continuous operation. The test sensor and the reference radiometer are located outside the blackbody exit in a test plane at a fixed distance from the blackbody aperture. The variation in the incident heat flux level at the sensor location is obtained by varying the VTBB temperature. The distance between the blackbody exit and the test plane is about $12.5 \mathrm{~mm}$ for calibrations up to $50 \mathrm{~kW} / \mathrm{m}^{2}$. For 
calibrations in the lower ranges of $25 \mathrm{~kW} / \mathrm{m}^{2}$ and $10 \mathrm{~kW} / \mathrm{m}^{2}$, the corresponding distances are about $62 \mathrm{~mm}$ and $140 \mathrm{~mm}$, respectively.

After stabilization of the temperature, the blackbody unit is positioned in front of the radiometer and the test sensor, sequentially. The output signals are recorded for the test duration in approximately $0.4 \mathrm{~s}$ intervals. The sensor responsivity is calculated by a linear regression fit to the sensor signal $(\mathrm{mV})$ data for different values of incident flux $\left(\mathrm{kW} / \mathrm{m}^{2}\right)$ measured by the radiometer. The measured responsivity of the sensor is expressed in $\mathrm{mV} /\left(\mathrm{kW} / \mathrm{m}^{2}\right)$. The regression curve fit for the data is generally linear with regression factors close to unity. The relative expanded total uncertainty (U) expressed for a coverage factor of $k=2$, is about $2 \%$.

\subsection{Heat Flux Gauge Manufacturer}

Medtherm Incorporated normally supplies a calibration curve for each total heat flux gauge they deliver. For this study the calibrations were carried out prior to shipping of the gauges, but the results were not provided to NIST until a given round robin was completed.

\section{RESULTS}

\subsection{First Round Robin}

Each fire laboratory reported the results for the calibrations of the two heat flux gauges in terms of the coefficients determined from linear least squares curve fits of the data when plotted as $\mathrm{kW} / \mathrm{m}^{2}$ versus the response of the gauge in $\mathrm{mV}$. In some cases the $y$-intercept was forced to pass through the plot origin, while in others it was allowed to "float," and a y-intercept value from the fit is reported. Normal laboratory protocols were followed.

There are many different approaches that might be used to compare the results from different laboratories. Two are used here. The first is to graphically compare the calculated lines for heat flux versus gauge reading. Since the y-intercepts are close to zero for those fits that were allowed to float, this is nearly the same as comparing the slopes for the lines. The second method was to compare the predicted heat flux readings corresponding to the nominal full-scale voltage outputs $(10 \mathrm{mV})$ for the gauges.

Table 2 lists first round-robin results for the Schmidt-Boelter gauge as intercepts (calculated value or zero if forced through origin) and slopes of linear least squares curve fits of imposed heat flux versus gauge reading in $\mathrm{mV}$. Indicated uncertainties are values determined from linear regression analysis of fits to the experimental data and represent two standard deviations (i.e., coverage factor of $\mathrm{k}=2$ ). Note that these experimentally derived uncertainties should not be interpreted as total uncertainties for the calibrations. Figure 8 shows the results for the fire laboratories included in Table 2. There is some scatter in the data from the different laboratories, but in general the curves fall close together.

In order to assess the repeatability of the BFRL calibrations, the two gauges were initially calibrated three times on different days. After calibration by the other four fire laboratories, the gauges were returned to BFRL and were recalibrated. The three initial calibrations along with 
Table 2. Results of Linear Least Squares Curve Fits to Calibrations for the SchmidtBoelter Gauge Used in the First Round Robin

\begin{tabular}{ccccc}
\hline \hline & \multicolumn{2}{c}{ y-intercept } & \multicolumn{2}{c}{ Slope } \\
\hline Fire Laboratory & Value & Uncertainty & Value & Uncertainty \\
\hline SP & 0.375 & 0.009 & 9.055 & 0.002 \\
BRE/FRS & -0.40 & 0.20 & 8.51 & 0.05 \\
FM Global & 0.0 & -- & 8.99 & 0.06 \\
SINTEF & 0.0 & 0.04 & 9.42 & 0.11 \\
BFRL & -0.03 & 0.04 & 9.24 & 0.04 \\
\hline
\end{tabular}

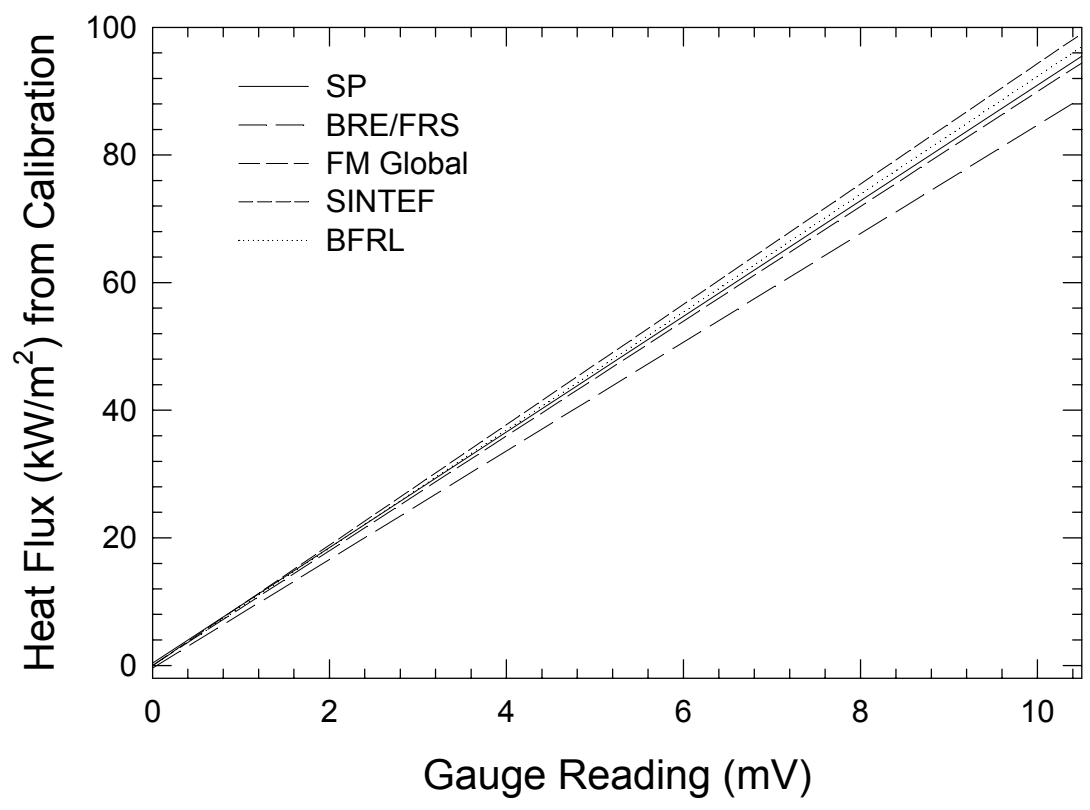

Figure 8. Calibration results from the five participating fire laboratories for the SchmidtBoelter total heat flux gauge used during the first round robin are plotted as heat flux versus gauge reading.

post-round robin results for the Schmidt-Boelter gauge are shown in Fig. 9. Results for a calibration made following the return of the gauge from LNE and PL are also included in the figure and will be discussed below. All of the calibration curves fall close together for the Schmidt-Boelter gauge (Table 3). The small uncertainties based on the experimental data for the intercepts and slopes reflect the high quality of the linear fits. Correlation coefficients, $R$, for the fits were higher than 0.9999. Even though small, differences between the various calibrations are somewhat larger than can be explained based simply on the statistics of curve fitting. The scatter in the repeated calibrations is much smaller than the differences between laboratories evident in Fig. 8 and summarized in Table 2. This indicates that the variations observed between calibrations at the different laboratory are not due to changes in the gauge during the round robin.

The Gardon gauge used in the first round robin was calibrated in the same way as described above for the Schmidt-Boelter gauge. Figure 10 compares the results from the participating fire 


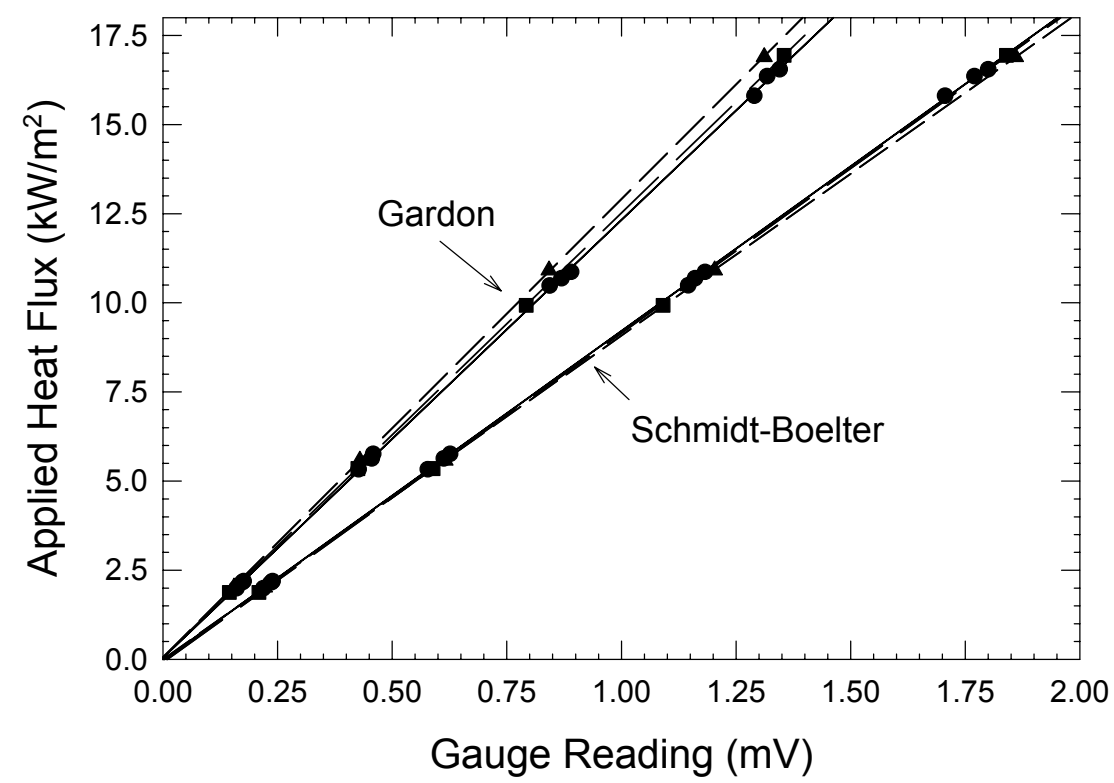

Figure 9. Results of repeated calibrations by BFRL of the two gauges used during the first round of the round robin are plotted as applied heat flux versus gauge reading. Symbols correspond to: - repeated calibrations at the start of the round robin, - results following calibrations by the fire laboratories, and $\Delta$ results following calibrations by the measurement laboratories.

Table 3. Results of Linear Least Squares Curve Fits to Repeated BFRL Calibrations of the Schmidt-Boelter Gauge Used in the First Round Robin

\begin{tabular}{ccccc}
\hline \hline & \multicolumn{2}{c}{ y-intercept } & \multicolumn{2}{c}{ Slope } \\
\hline Calibration & Value & Uncertainty & Uncertainty \\
\hline 1 & -0.001 & 0.057 & 9.186 & 0.052 \\
2 & -0.035 & 0.036 & 9.250 & 0.033 \\
3 & -0.055 & 0.088 & 9.279 & 0.081 \\
$\begin{array}{c}\text { Post Round } \\
\text { Robin }\end{array}$ & -0.002 & 0.026 & 9.236 & 0.091 \\
Post Calibration & -0.001 & 0.027 & 9.082 & 0.023 \\
Labs & & & & \\
\hline
\end{tabular}

laboratories. Table 4 lists the y-intercepts (if reported) and slopes of the calibrations along with uncertainties determined from the fits.

For a given heat flux, the Gardon gauge generates roughly $25 \%$ less output voltage than the Schmidt-Boelter gauge, even though both gauges have the same nominal full-scale ranges. The calibration curves for both gauges have very similar behaviors. For both gauges the calibration lines determined by the various laboratories fall relatively close together. However, the differences between laboratories are apparently not random. The relative ordering of the lines is nearly the same for both gauges, with SINTEF measuring lower responses and BRE/FRS higher. The results for the three remaining laboratories are in between these limits and lie close together. 


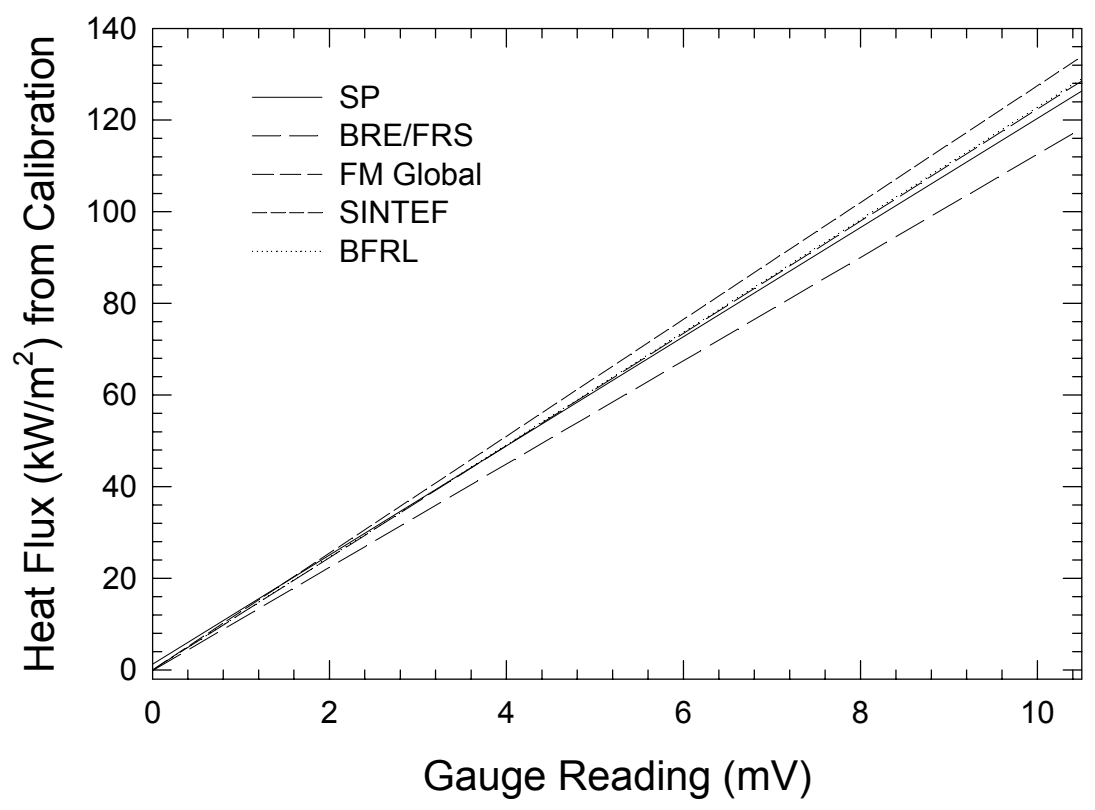

Figure 10. Calibration results from the five participating laboratories for the Gardon total heat flux gauge used during the first round robin are plotted as heat flux versus gauge reading.

Table 4. Results of Linear Least Squares Curve Fits to Calibrations for the Gardon Gauge Used in the First Round Robin

\begin{tabular}{ccccc}
\hline \hline & \multicolumn{2}{c}{ y-intercept } & \multicolumn{2}{c}{ Slope } \\
\hline Fire Laboratory & Value & Uncertainty & Value & Uncertainty \\
\hline SP & 1.26 & 0.04 & 11.912 & 0.009 \\
BRE/FRS & -0.14 & 0.08 & 11.27 & 0.03 \\
FM Global & 0.0 & -- & 12.24 & 0.06 \\
SINTEF & 0.0 & 0.04 & 12.76 & 0.08 \\
BFRL & 0.05 & 0.08 & 12.28 & 0.10 \\
\hline
\end{tabular}

Repeatability measurements for the Gardon gauge performed at NIST are plotted in Fig. 9 and are summarized in Table 5. With one exception, correlation coefficients, $R$, for the fits were higher than 0.9999. As found for the Schmidt-Boelter gauge, the measurements made at the start and end of the round robin agree well. Variations were considerably smaller than those found for calibrations performed at the different laboratories, confirming that differences between the various laboratories are not due to changes in the response of the gauge.

\subsection{Calibrations of First Round Gauges by the Manufacturer, LNE, and PL}

Following the completion of the first round robin, both gauges were sent to LNE and PL for independent calibration. During testing at LNE water flow to the Gardon gauge was inadvertently interrupted, and the gauge overheated. As a result, the surface was damaged. It was subsequently cleaned and repainted. Following their return to BFRL, the Schmidt-Boelter gauge and the refurbished Gardon gauge were recalibrated. Results for the two gauges are included in Fig. 9 and are summarized in Table 3 and Table 5. The calibration for the Schmidt- 
Table 5. Results of Linear Least Squares Curve Fits to Repeated BFRL Calibrations of the Gardon Gauge Used in the First Round Robin

\begin{tabular}{ccccc}
\hline \hline & \multicolumn{2}{c}{ y-intercept } & \multicolumn{2}{c}{ Slope } \\
\hline Calibration & Value & Uncertainty & Uncertainty \\
\hline 1 & 0.07 & 0.11 & 12.28 & 0.14 \\
2 & 0.04 & 0.16 & 12.35 & 0.19 \\
3 & 0.04 & 0.09 & 12.21 & 0.10 \\
Post Round & 0.07 & 0.02 & 12.45 & 0.03 \\
$\quad$ Robin & & 0.07 & 12.86 & 0.08 \\
Post Calibration & 0.05 & & & \\
Laboratories & & &
\end{tabular}

Boelter gauge agrees well with earlier calibrations, while the repaired Gardon gauge appears to be slightly less sensitive $(\approx 4 \%)$ than before it was damaged. Calibration results for the Gardon gauge reported for LNE are based on measurements recorded prior to the damage, while the PL Gardon gauge calibration was made using the refurbished device.

The results for the two measurement laboratories, along with the Medtherm calibration, are summarized in Table 6 and Table 7 for the Schmidt-Boelter and Gardon gauges, respectively. Uncertainty values provided by the laboratories are included and represent the total uncertainties with a coverage factor of $2(95 \%)$. The three calibrations are compared graphically in Fig. 11 and Fig. 12 for the Schmidt-Boelter and Gardon gauges. The results for the five fire laboratories are shown as dotted lines for comparison.

Table 6. Calibration Results from Two Measurement Laboratories and the Gauge Manufacturer for the Schmidt-Boelter Gauge Used in the First Round Robin

\begin{tabular}{cccc}
\hline \hline Laboratory & y-intercept & Slope & Combined Uncertainty \\
\hline LNE & 0.37 & 8.995 & $<3 \%$ \\
PL & -- & 8.640 & $2.1 \%$ \\
Medtherm & -- & 8.826 & $3 \%$ \\
\hline
\end{tabular}

Table 7. Calibration Results from Two Measurement Laboratories and the Gauge Manufacturer for the Gardon Gauge Used in the First Round Robin

\begin{tabular}{cccc}
\hline \hline Laboratory & y-intercept & Slope & Combined Uncertainty \\
\hline LNE & 0.62 & 12.083 & $<3 \%$ \\
PL & -- & 11.73 & $2.1 \%$ \\
Medtherm & -- & 11.481 & $3 \%$ \\
\hline
\end{tabular}

For both gauges the calibrations by the measurement laboratories and the manufacturer fall near the mid-ranges of those recorded by the fire laboratories and are also seen to fall relatively close together. However, as observed for the fire laboratory calibrations, there does seem to be a pattern in the results. For both gauges, LNE reported that the heat flux gauges were slightly less sensitive than indicated by Medtherm and PL. PL measured a slightly higher sensitivity for the Schmidt-Boelter gauge than reported by Medtherm, while the opposite was true for the Gardon gauge. If the $4 \%$ increase in the slope of the calibration line for the refurbished Gardon gauge 


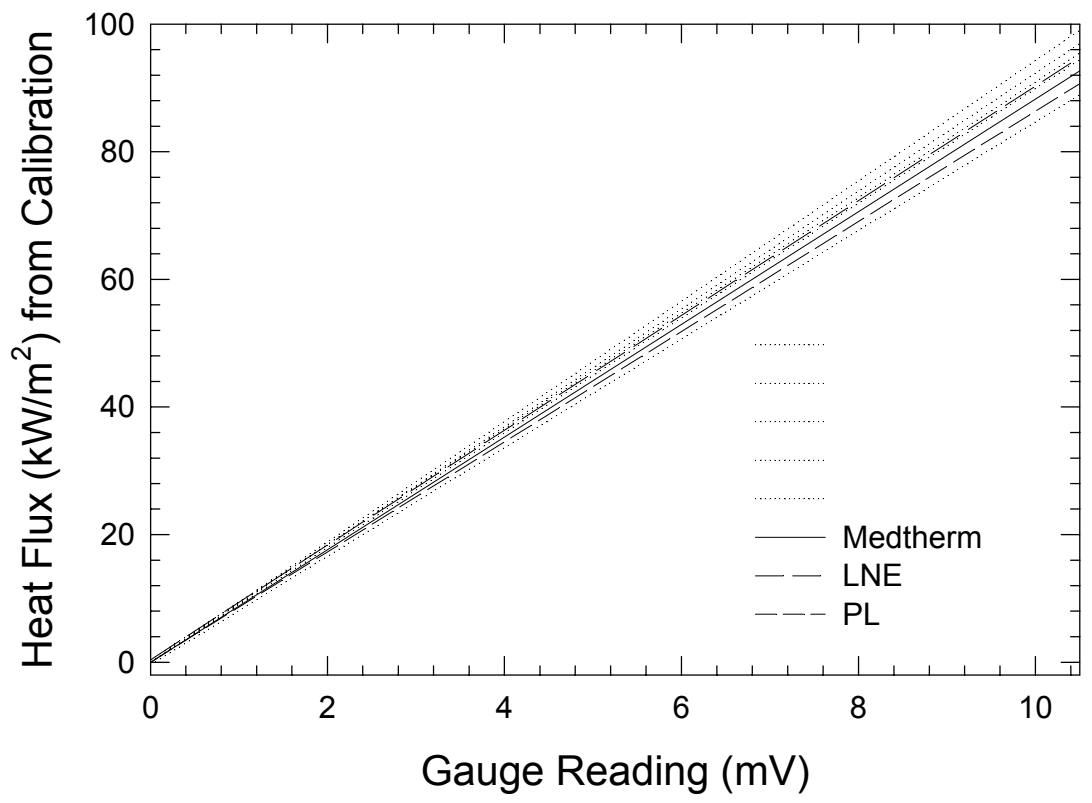

Figure 11. Calibration results by the gauge manufacturer, LNE, and PL for the SchmidtBoelter total heat flux gauge used during the first round robin are plotted as heat flux versus gauge reading. The results for the five fire laboratories shown in Fig. 8 are included as dotted lines.

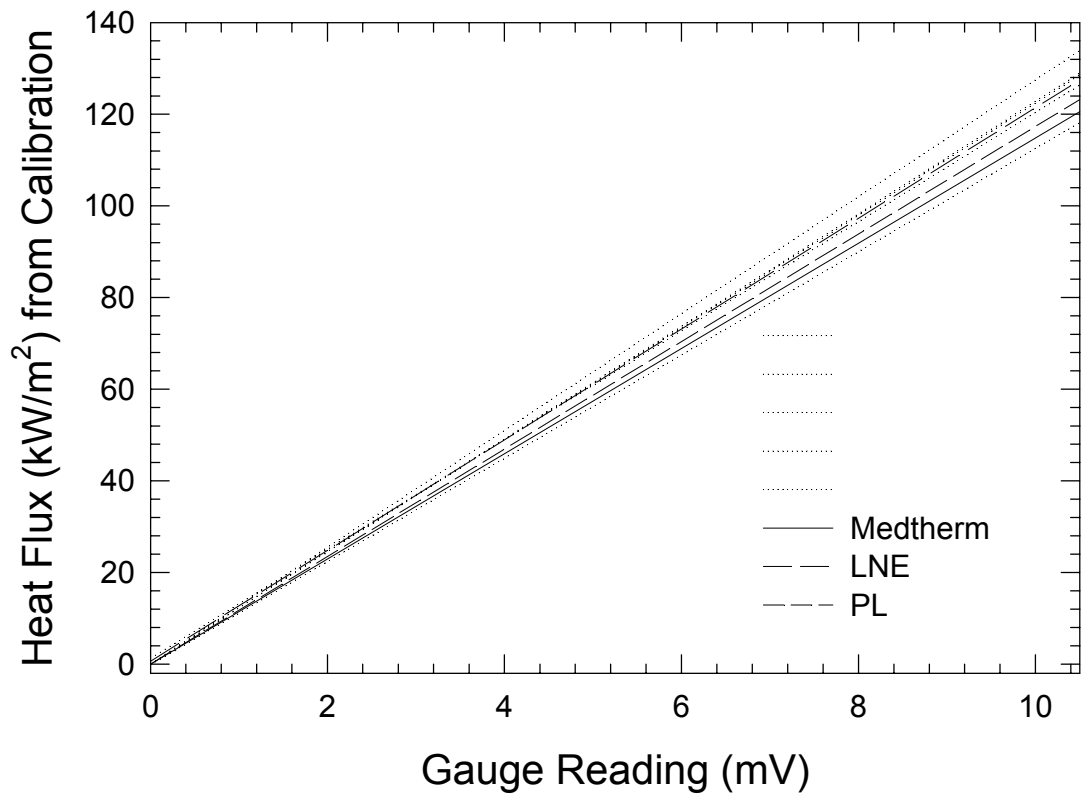

Figure 12. Calibration results by the gauge manufacturer, LNE, and PL for the Gardon total heat flux gauge used during the first round robin are plotted as heat flux versus gauge reading. The results for the five fire laboratories shown in Figure 10 are included as dotted lines.

determined by BFRL is taken into account, the PL calibration curve for this gauge will fall below that reported by Medtherm, consistent with the Schmidt-Boelter results. This suggests that there 
are small systematic differences between calibrations performed by the fire laboratories, measurement laboratories, and manufacturer.

\subsection{Second Round Robin}

As an additional check of the results, the five fire laboratories conducted a second round robin utilizing new Schmidt-Boelter and Gardon gauges and the same protocol as for the first round robin.

Table 8 lists results for the Schmidt-Boelter gauge for the second round robin, and Fig. 13 shows plots of the data. Repeatability tests made by BFRL are summarized in Table 9 for the three initial calibrations and for a fourth calibration following the return of the gauge to BFRL after calibration by the other fire laboratories. The data exhibit a high degree of linearity with correlation coefficients, $R$, of 0.9999 or better. The results are shown graphically in Fig. 14 and indicate the Schmidt-Boelter gauge was stable during the course of the round robin tests.

Table 8. Results of Linear Least Squares Curve Fits to Calibrations for the SchmidtBoelter Gauge Used in the Second Round Robin

\begin{tabular}{ccccc}
\hline \hline & \multicolumn{2}{c}{ y-intercept } & \multicolumn{2}{c}{ Slope } \\
\hline Laboratory & Value & Uncertainty & Value & Uncertainty \\
\hline SP & 0.21 & 0.15 & 12.54 & 0.04 \\
BRE/FRS & 0.8 & 0.4 & 11.31 & 0.13 \\
FM Global & 0.0 & -- & 12.52 & 0.08 \\
SINTEF & 0.0 & 0.04 & 13.8 & 0.3 \\
BFRL & -0.04 & 0.04 & 12.79 & 0.06 \\
\hline
\end{tabular}

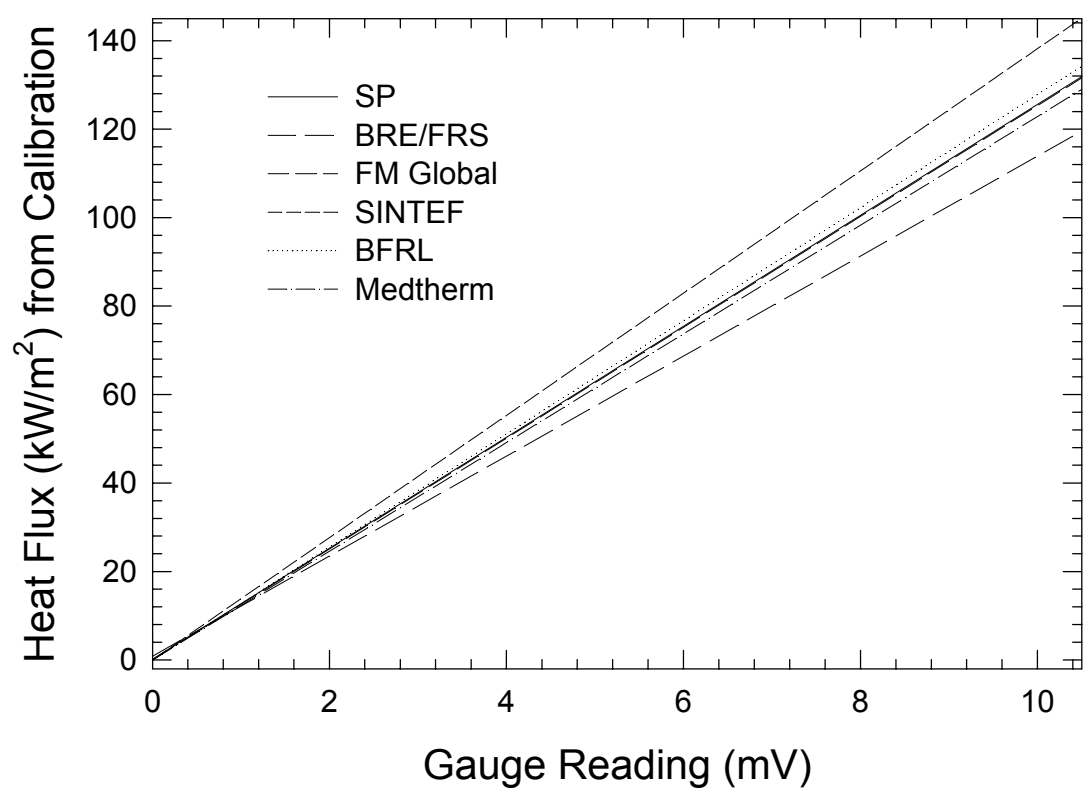

Figure 13. Calibration results from the five participating laboratories for the SchmidtBoelter total heat flux gauge used during the second round robin are plotted as heat flux versus gauge reading. The result for the gauge manufacturer is included for reference. 
Table 9. Results of Linear Least Squares Curve Fits to Repeated BFRL Calibrations of the Second Schmidt-Boelter Gauge

\begin{tabular}{ccccc}
\hline \hline & \multicolumn{2}{c}{ y-intercept } & \multicolumn{3}{c}{ Slope } \\
\hline Calibration & Value & Uncertainty & Value & Uncertainty \\
\hline 1 & -0.03 & 0.07 & 12.77 & 0.10 \\
2 & -0.04 & 0.11 & 12.81 & 0.14 \\
3 & -0.06 & 0.08 & 12.78 & 0.10 \\
Post Round & -0.05 & 0.07 & 12.90 & 0.09 \\
Robin & & & & \\
\hline
\end{tabular}

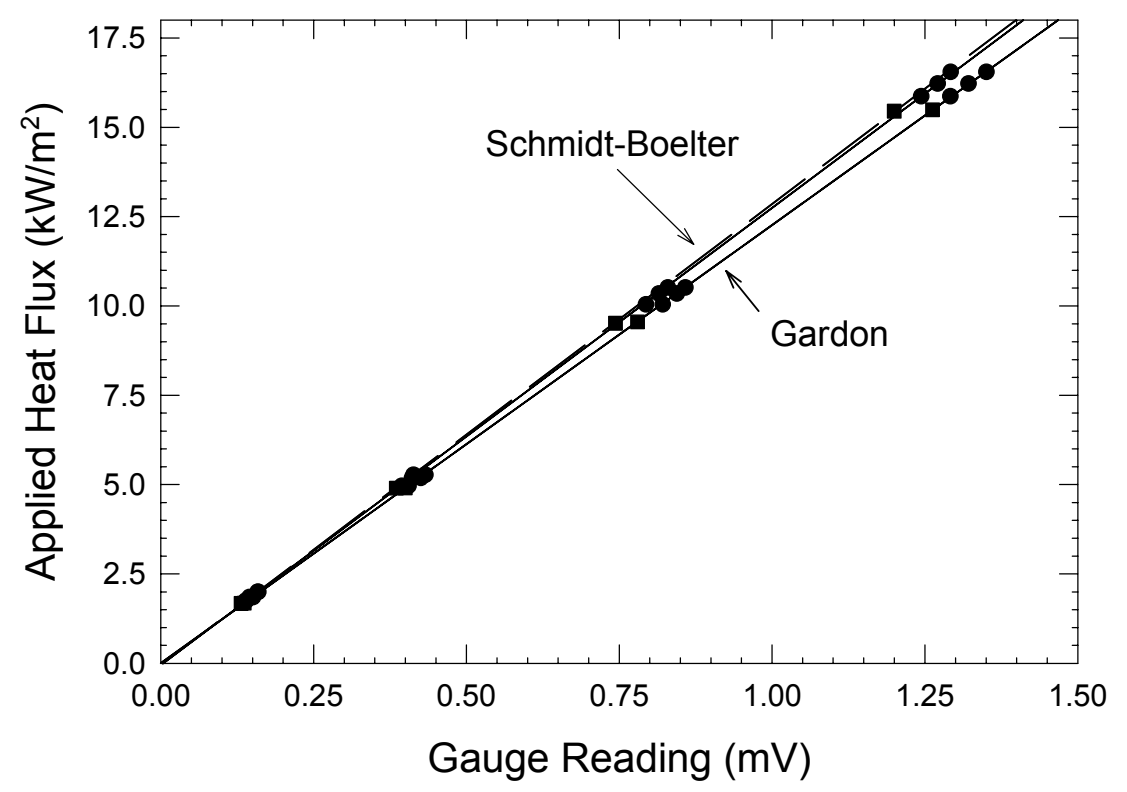

Figure 14. Results of repeated calibrations by BFRL of the two gauges used during the second round robin are plotted as applied heat flux versus gauge reading. Symbols correspond to: - repeated calibrations at the start of the round robin and calibration following calibrations by the fire laboratories.

Table 10 and Fig. 15 provide the corresponding results for the Gardon gauge. The results of repeated calibrations at BFRL for this gauge are summarized in Table 11 and plotted in Fig. 14. The reproducibility was extremely good and the linearity is high as indicated by $R$ values for the fits, which were higher than 0.9999 . The close agreement of the calibrations provides additional support for the conclusion that the change in response for the Gardon gauge used in the first round robin was associated with its overheating and repainting.

As for the first round robin, Medtherm provided calibrations to BFRL for the two gauges after the completion of the round robin. Calibration results and reported total uncertainties are listed in Table 12. Results for the two gauges have been included in Fig. 13 and Fig. 15 for comparison purposes.

These calibrations indicate that the Gardon gauge used in the second round robin was slightly more sensitive than the Schmidt-Boelter gauge. As expected, calibration curves for all of the 
Table 10. Results of Linear Least Squares Curve Fits to Calibrations for the Gardon Gauge Used in the Second Round Robin

\begin{tabular}{ccccc}
\hline \hline & \multicolumn{2}{c}{ y-intercept } & \multicolumn{2}{c}{ Slope } \\
\hline Laboratory & Value & Uncertainty & Value & Uncertainty \\
\hline SP & 0.9 & 0.2 & 11.68 & 0.06 \\
BRE/FRS & 1.11 & 0.51 & 10.96 & 0.18 \\
FM Global & 0.0 & -- & 12.22 & 0.07 \\
SINTEF & 0.00 & 0.04 & 13.1 & 0.4 \\
BFRL & 0.00 & 0.03 & 12.26 & 0.03 \\
\hline
\end{tabular}

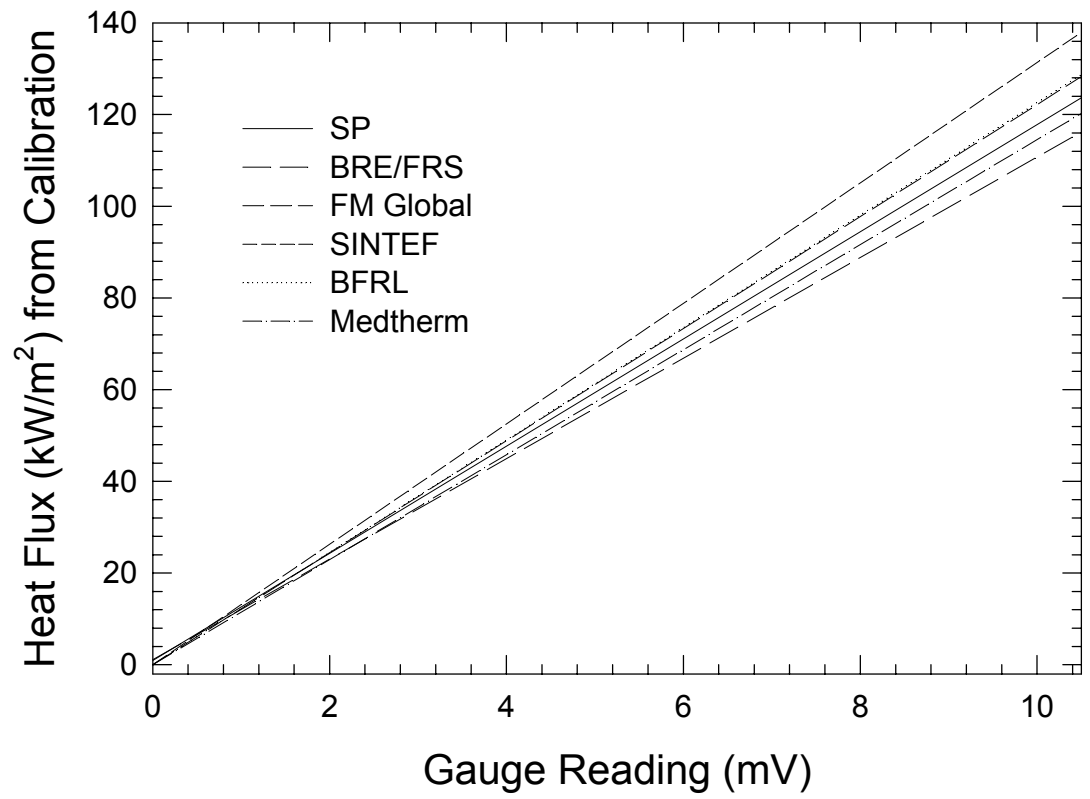

Figure 15. Calibration results from the five participating laboratories for the Gardon total heat flux gauge used during the second round robin are plotted as heat flux versus gauge reading. The result for the gauge manufacturer is included for reference.

Table 11. Results of Linear Least Squares Curve Fits to Repeated BFRL Calibrations of the Second Gardon Gauge

\begin{tabular}{ccccc}
\hline \hline & \multicolumn{2}{c}{ y-intercept } & \multicolumn{2}{c}{ Slope } \\
\hline Calibration & Value & Uncertainty & Value & Uncertainty \\
\hline 1 & -0.02 & 0.03 & 12.29 & 0.04 \\
2 & 0.01 & 0.05 & 12.24 & 0.06 \\
3 & 0.01 & 0.07 & 12.26 & 0.08 \\
$\begin{array}{c}\text { Post Round } \\
\text { Robin }\end{array}$ & 0.01 & 0.02 & 12.26 & 0.03 \\
\hline
\end{tabular}

gauges used in both round robins have similar behaviors. As observed during the first round robin, results from SINTEF lie somewhat above those for the other fire laboratories when plotted as applied heat flux versus gauge reading, three of the laboratories report similar intermediate values, and the BRE/FRS curves are the lowest. For both gauges the Medtherm calibrations fall 
Table 12. Manufacturer Calibrations Results for the Schmidt-Boelter and Gardon Gauges Used during the Second Round Robin

\begin{tabular}{ccc}
\hline \hline Gauge & Slope & Combined Uncertainty \\
\hline Schmidt-Boelter & 12.285 & $3 \%$ \\
Gardon & 11.455 & $3 \%$ \\
\hline
\end{tabular}

above the BRE/FRS result, but lie below the curves reported by SP, FM Global, BFRL, and SINTEF.

\subsection{Comparisons Based on Predicted Full Scale Gauge Responses}

Predicted heat flux values corresponding to full-scale responses are used to provide quantitative assessment of the agreement of calibrations from the different laboratories. Figure 16 shows the predicted heat fluxes corresponding to a full-scale voltage output, $10 \mathrm{mV}$, for the gauges used in the first round robin. Predictions based on calibrations for the fire and measurement laboratories are plotted as functions of the manufacturer's calibration. Error bars represent $95 \%$ confidence intervals for the predicted values based on linear regression analysis of the calibration measurements.

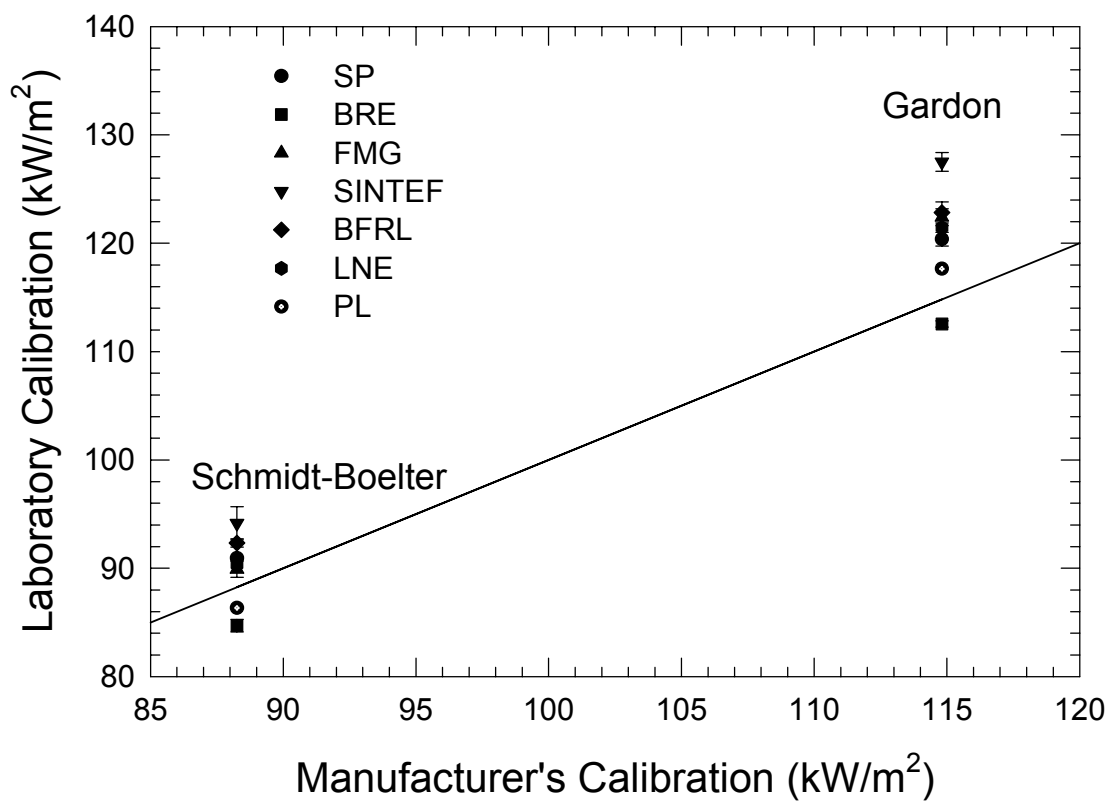

Figure 16. Calibration results for the five fire laboratories and two measurement laboratories are compared for the two gauges used during the first round robin by plotting the predicted full scale responses (i.e., the heat flux corresponding to a $10 \mathrm{mV}$ gauge output) versus the manufacturer's results (line). Uncertainties based on experimental results and determined as described in the text are indicated for the results from the fire laboratories.

The averages and scatter $(2 \sigma)$ for the results from the five fire laboratories are $90.4 \mathrm{~kW} / \mathrm{m}^{2} \pm 7.2$ $\mathrm{kW} / \mathrm{m}^{2}$ and $121.2 \mathrm{~kW} / \mathrm{m}^{2} \pm 11.0 \mathrm{~kW} / \mathrm{m}^{2}$ for the Schmidt-Boelter and Gardon gauges, respectively. The variations correspond to about $\pm 8.0 \%$ and $\pm 9.1 \%$ of the two averaged values, respectively. The averages can be compared to the corresponding results based on the 
manufacturer's calibrations of $88.3 \mathrm{~kW} / \mathrm{m}^{2}$ and $114.8 \mathrm{~kW} / \mathrm{m}^{2}$. The averaged values from the fire laboratory calibrations are $2.4 \%$ and $5.5 \%$ higher than those based on the manufacturer's calibration for the Schmidt-Boelter and Gardon gauges, respectively.

The LNE and PL predicted full-range values are $90.3 \mathrm{~kW} / \mathrm{m}^{2}$ and $86.3 \mathrm{~kW} / \mathrm{m}^{2}$ for the SchmidtBoelter gauge, differing from the fire laboratory averages by $-0.1 \%$ and $-4.5 \%$, respectively. For the Gardon gauge the LNE and PL results are $121.4 \mathrm{~kW} / \mathrm{m}^{2}$ and $117.6 \mathrm{~kW} / \mathrm{m}^{2}$, which differ from the fire laboratory averages by $+0.1 \%$ and $-3.1 \%$. It should be kept in mind that the response of the Gardon gauge was changed slightly between the times when LNE and PL made their calibrations.

Due the limited number of measurements and the damage to the Gardon gauge, it is difficult to compare the results from LNE and PL. Even so, it appears that there are small systematic differences between the calibration results for the two laboratories. These differences just fall within the combined $2 \sigma$ uncertainties reported by these laboratories.

The close agreement between calibrations recorded by the fire laboratories and the two measurement laboratories shows that the fire laboratories' calibrations agree well with each other and provide results that fall within a few percent of the actual heat flux.

Figure 17 compares predicted full-scale heat fluxes based on the fire laboratory calibrations for the gauges used in the second round robin. Averages and scatter $(2 \sigma)$ for the five fire laboratories are $126.2 \mathrm{~kW} / \mathrm{m}^{2} \pm 17.3 \mathrm{~kW} / \mathrm{m}^{2}$ and $124.7 \mathrm{~kW} / \mathrm{m}^{2} \pm 21.2 \mathrm{~kW} / \mathrm{m}^{2}$ for the SchmidtBoelter and Gardon gauges, respectively. The variations correspond to $13.7 \%$ and $17.0 \%$, respectively, which are somewhat larger than observed during the first round robin.

\section{DISCUSSION}

Given the significant differences between the calibration methods used in the various fire laboratories, the agreement for the calibrations, as reflected by the variations from the average values for the nominal full-scale readings of the four gauges, is viewed as good. However, there are systematic variations in calibration results. SINTEF reported the lowest sensitivity for the two gauges tested during the first round robin, while BRE/FRS reported the highest. When the results from these two fire laboratories are omitted, average and scatter $(2 \sigma)$ full-scale heat flux values for the three remaining laboratories become $91.1 \mathrm{~kW} / \mathrm{m}^{2} \pm 2.5 \mathrm{~kW} / \mathrm{m}^{2}(2.7 \%)$ and 121.9 $\mathrm{kW} / \mathrm{m}^{2} \pm 2.7 \mathrm{~kW} / \mathrm{m}^{2}(2.2 \%)$. The variations are reduced by factors of 3 and 4 from those when results for all five laboratories are included.

The same relative ordering of predicted full-scale heat flux readings among the fire laboratories was found for the two gauges used in the second round robin. Averages and variations for the gauge responses change to $126.2 \mathrm{~kW} / \mathrm{m}^{2} \pm 2.8 \mathrm{~kW} / \mathrm{m}^{2}(2.2 \%)$ for the Schmidt-Boelter gauge and $124.9 \mathrm{~kW} / \mathrm{m}^{2} \pm 12.9 \mathrm{~kW} / \mathrm{m}^{2}(9.9 \%)$ for the Gardon gauge when the high and low results are omitted. For the second round robin Schmidt-Boelter gauge, the reduction in the scatter gained by omitting the high and low calibration values is comparable to the first round result. However, for the Gardon gauge the reduction is less than a factor of one, compared to a factor of four for the first round results. This is due to a larger scatter between measurements from the three 


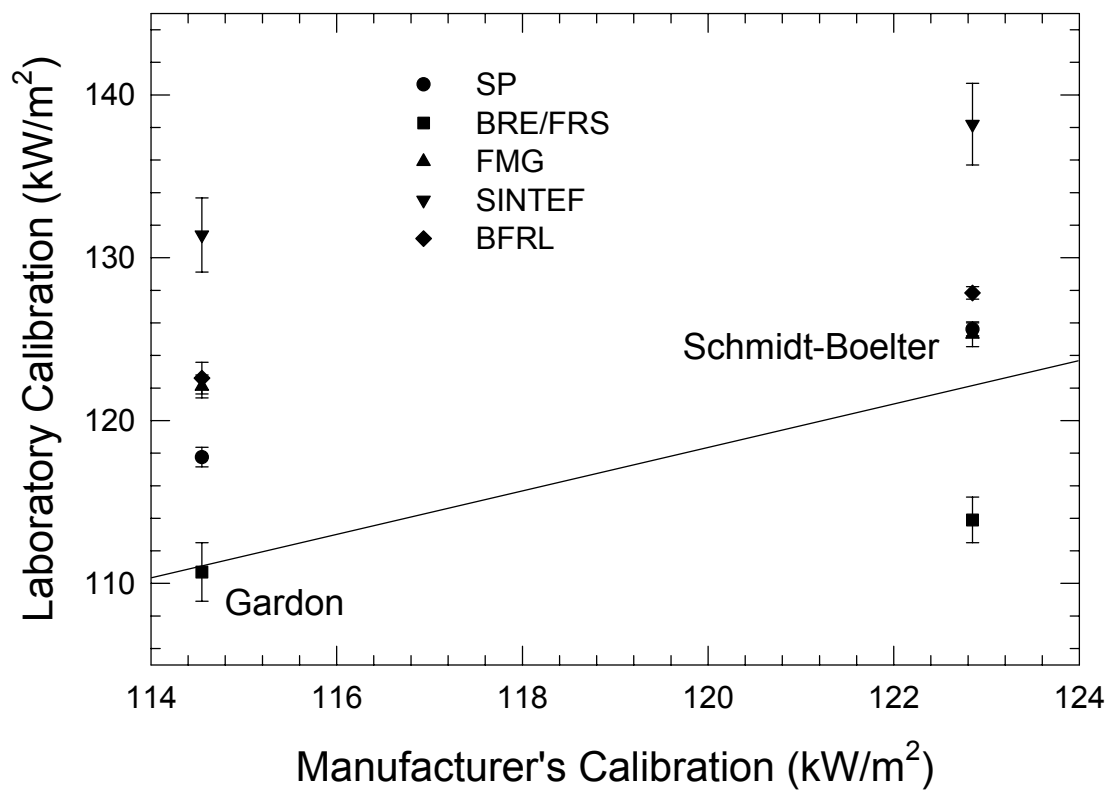

Figure 17. Calibration results for the five fire laboratories are compared for the two gauges used during the second round robin by plotting the predicted full scale responses (i.e., the heat flux corresponding to a $10 \mathrm{mV}$ gauge output) versus the manufacturer's results (line). Uncertainties based on experimental results and determined as described in the text are indicated.

remaining fire laboratories for this Gardon gauge than observed for the other three sets of calibrations.

There is a plausible explanation that partially explains the lower responses recorded by the SINTEF calibration system as compared to the other fire laboratories. As noted earlier, the SINTEF calibration method uses a full-hemisphere radiant source, while the systems used by the other fire laboratories constrain the thermal radiation striking the gauges to narrower angles. FM Global measured the angular sensitivities of the two gauges used for the first round robin. The results are shown in Fig. 18 and Fig. 19. In the top panels, the responses of the gauges have been normalized by the responses recorded for normal incidence $(\theta=0)$ and plotted against incident angle $(\theta)$ for the thermal radiation. In the lower panel the normalized response is divided by $\cos (\theta)$ and again plotted against incident angle. If the gauge had a perfect angular response, the result would be a constant value of 1 for all incident angles for the lower plot.

It is clear from the results in the lower panels of Fig. 18 and Fig. 19 that the responses of the two gauges fall below the idealized cosine response for large incidence angles. The angular dependencies were fit using an equation of the form,

$$
\frac{\pi / 2-\theta}{\pi / 2-\theta-\varepsilon \theta^{2}}
$$

where $\varepsilon$ is a parameter to be determined. The results were $\varepsilon=0.018$ and $\varepsilon=0.025$ for the Schmidt-Boelter and Gardon gauges, respectively. The resulting curves are included as solid 

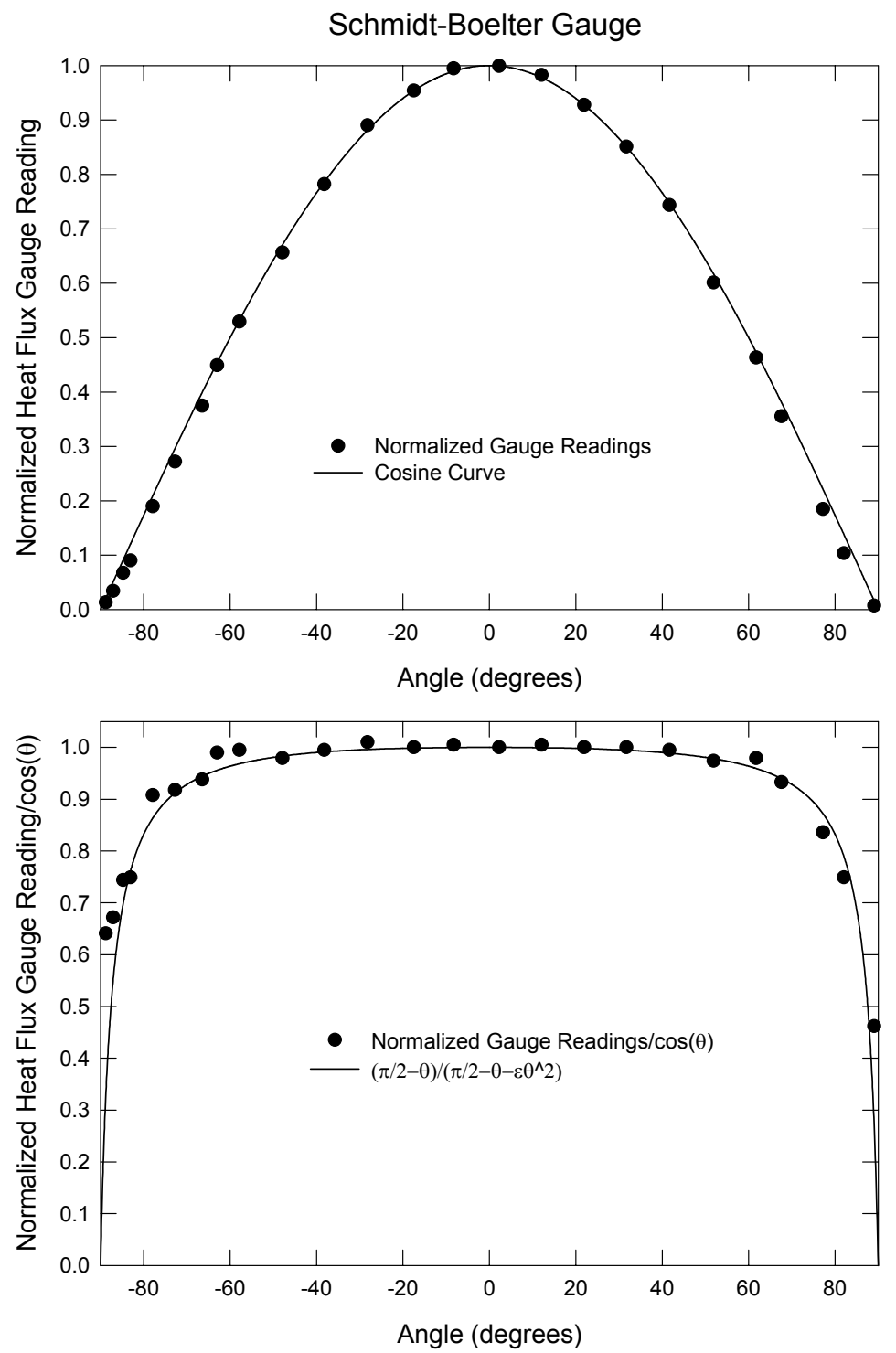

Figure 18. The angular response recorded by FM Global for the Schmidt-Boelter gauge used during the first round robin is shown in the top graph as normalized gauge response versus radiation angle. The data are replotted in the lower graph after dividing the normalized gauge response by the cosine of the incident angle $(\theta)$. The solid line is the result of a fit of the experimental data to the indicated form with $\varepsilon=\mathbf{0 . 0 1 8}$.

lines in the lower panels of Fig. 18 and Fig. 19. By integration, the areas under the curves were determined, and it was found that that the ratios of absorbed heat flux for the devices were reduced by 0.97 and 0.96 for the Schmidt-Boelter and Gardon gauges, respectively, when compared to those assuming a perfect cosine angular dependence. Since most of the fall off in sensitivity occurs for large $\theta$, these ratios should provide good approximations for the expected reductions in sensitivity when narrow-angle and hemispherical calibrations are compared. The angular effects have the correct sign to explain the lower sensitivities reported by SINTEF for the four gauges. The magnitudes are consistent with observed differences between the average 



Figure 19. The angular response recorded by FM Global for the Gardon gauge used during the first round robin is shown in the top graph as normalized gauge response versus incidence angle. The data are replotted in the lower graph after dividing the normalized gauge response by the cosine of the incident angle $(\theta)$. The solid line is the result of a fit of the experimental data to the indicated form with $\varepsilon=0.025$.

values for the fire labs and the SINTEF measurement values for the first round robin, but only partially compensate for those reported by SINTEF for the second round robin.

The variations in calibrated heat flux gauge response between the fire laboratories are larger than the calibration repeatability for individual laboratories as shown by the consistent ordering of results for the four gauges and the relatively small uncertainties in data fits from individual laboratories. These observations indicate that there are systematic variations between results from the fire laboratories. In addition to angular sensitivity, there are a number of additional gauge response and calibration system parameters that might result in such systematic variations. 
These include wavelength sensitivity, relative responses to convective and radiative heat transfer, and non-linear gauge response. A variety of calibration system parameters can also introduce differences. Systems that utilize a secondary standard are linearly dependent on its calibration. Any variations between the calibration standards between laboratories should appear as differences in the results. Secondary standards have all of the potential sensitivities listed above that can impact the calibrations. Some of the laboratories' calibration systems require a number of additional measurements such as black-body temperature, distance from the source, and the angle of the radiative source observed. Any uncertainties in these measurements propagate into the final calibration result.

The results allow some analysis of the relative effects of potential error sources. Four of the fire laboratories found that their calibration data plotted as applied heat flux versus gauge response could be fit to straight lines with high precision, as reflected by correlation coefficients that were generally higher than 0.9999. In contrast, SINTEF found indications of nonlinear gauge responses that appeared to increase with applied heat flux. Based on their results, these researchers have concluded that a better characterization of the linearity of gauge response should be available before calibrations are routinely extended beyond the heat flux range over which they are calibrated.

Additional insight into the possible role of nonlinearity of gauge response on the calibrations is obtained by considering the extrapolated full-range readings reported for the four gauges that were calibrated. Due to the wide variation in the maximum heat flux applied to the gauges (see the values included for the individual laboratories in Section 3.2) for the calibrations, the amount of extrapolation required to estimate a full-scale heat flux reading varied substantially among the fire laboratories. Since any nonlinearity in the response will affect the accuracy of such extrapolations, the absence of large variations in the extrapolated full-range values suggests that nonlinearity in gauge response is not introducing significant differences.

Researchers at SP used the results of their calibrations to perform a more detailed analysis concerning the linearity of the calibrations. Figure 20 shows plots of residuals from the linear least squares curve fits versus the gauge reading for each of the four gauges calibrated during the two round robins. As expected, the residuals are small for both types of gauges. Interestingly, the magnitudes of the residuals for the Gardon gauges are somewhat larger and, while the residuals for the Schmidt-Boelter gauge appear to be randomly distributed, systematic variations with gauge reading are observed. Such variations indicate that the responses of the Gardon gauges are slightly nonlinear. In fact, a second order curve was found to fit the results for the Gardon gauges more accurately than linear fits. This observation does not mean that the gauge response is second order, but provides further evidence that Gardon gauge response is more nonlinear than for a Schmidt-Boelter gauge.

Due to the wide variety of heat flux sources (see Table 1) and the different calibration heat flux levels used, the source temperatures varied over an extensive range both during a given calibration as well as between laboratories. As a result, the wavelength distributions for the sources varied substantially as well. The linear response of the gauges, as well as the ability to substantially extrapolate from the measured results with good agreement between laboratories, 

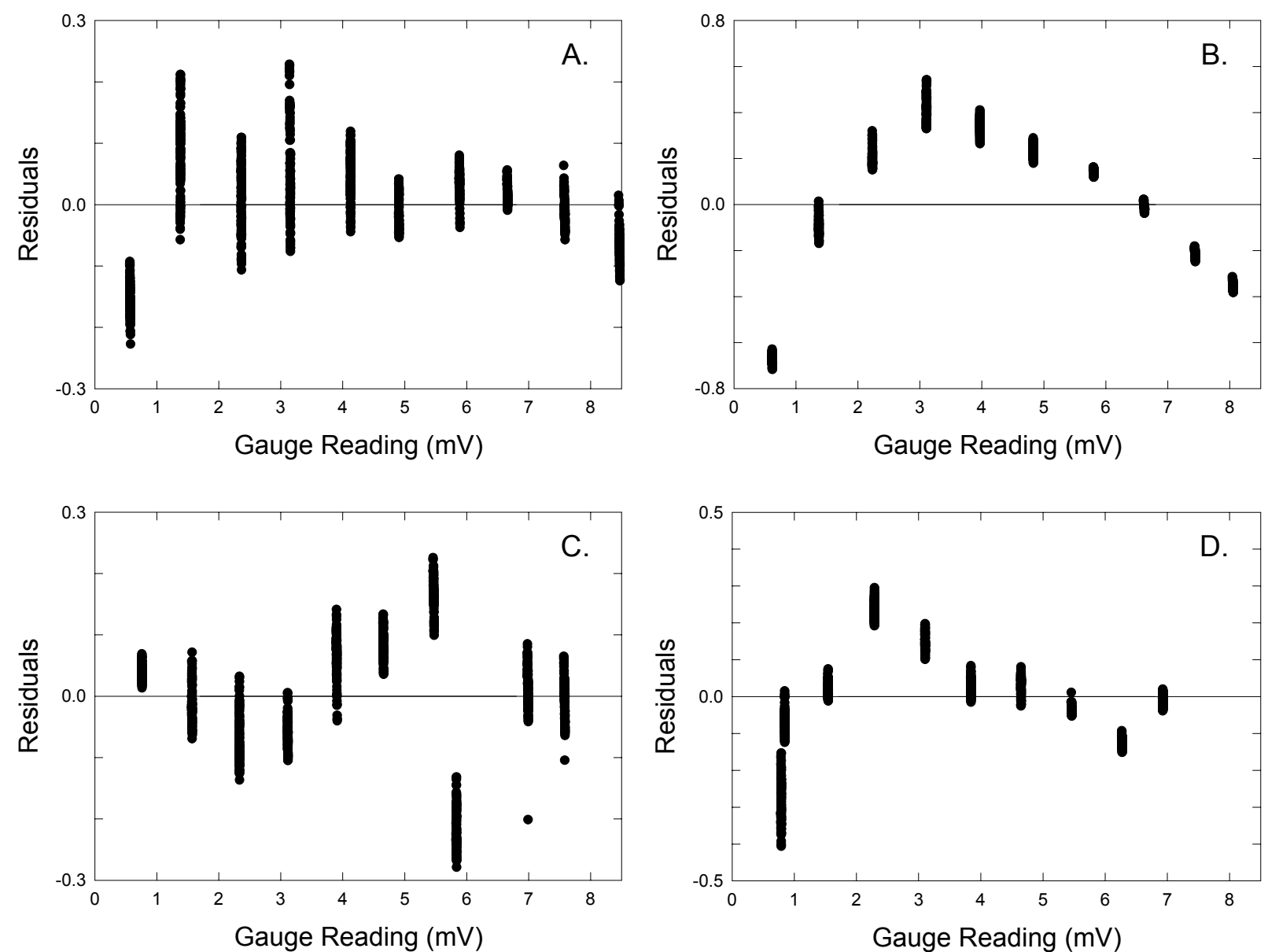

Figure 20. Residuals derived from linear least squares curve fits to calibration results recorded by SP are plotted as a function of the gauge reading in millivolts for the A) first round Schmidt-Boelter gauge, B) first round Gardon gauge, C) second round Schmidt-Boelter gauge, and D) second round Gardon gauge.

indicates that the high absorbance coatings used on the gauges have nearly flat wavelength responses over the relevant wavelength range.

Heat flux gauges are often calibrated assuming that radiative heating is the only heat transfer mode. However, both Gardon and Schmidt-Boelter gauges are sensitive to the convective heat transfer that occurs when the gas temperature at the gauge surface is different than the gauge surface temperature. Due to differences between the calibration facilities, there is the potential for significant variations in the relative contributions of convective heat transfer to gauge response. The relatively close agreement of the calibration results between fire laboratories suggests that variations in the relative contributions of convective heat transfer to the total heat transfer to the gauge have only small effects on the calibrations. It should be noted that this does not imply that convective heat transfer processes are absent in a given calibration system, but only that their effects are cancelled out in some manner. For instance, in experiments utilizing secondary-standard gauges, the convective component will have no effect on the calibration if it makes the same contribution as for the gauge being calibrated. 
It is worthwhile to emphasize again that the degree of agreement for calibrations performed in the different laboratories is viewed as satisfactory for fire test needs. It does appear that there is room for improvement in calibration consistency based on more carefully controlled experiments and analysis. Before undertaking such an effort, it is important to consider whether the potential improved agreement between fire laboratories justifies the associated costs and the need for modifying current calibration practices.

\section{SUMMARY}

The results of the two round robins of heat flux gauge calibrations have demonstrated that the agreement between the five fire laboratories is satisfactory for most fire research purposes and standard fire testing. Absolute values and variations in results between these laboratories are comparable to those reported by measurement laboratories. Systematic variations observed in the results suggest it should be possible to further improve agreement between calibration results from the fire laboratories.

It should be recognized that the data presented in this publication are representative of the calibration procedures at the fire laboratories at a particular moment in time. There are a number of ongoing activities in the area of heat flux gauge calibrations at the fire laboratories and elsewhere with the aim of improving the understanding of heat flux gauge calibration methodologies and improving the agreement between laboratories.

\section{RECOMMENDATIONS}

The role of convective heat transfer in the response of gauges sensitive to both radiation and convection is not very well understood and needs to be elucidated, both for calibration purposes and for their use in fire tests and other applications. The absorptivity, which is a property of the surface coating, also requires additional study because it affects the relative amounts of radiative and convective heat transfer to the gauge surface.

When the calibration is performed as a transfer calibration the uncertainty analysis should also consider the influence of the reference gauge being of a different type than the one being calibrated. Gardon and Schmidt-Boelter gauges are not equally sensitive to convection, and the error due to convection can therefore be greater if the reference and calibration gauge are of different types.

Finally the FORUM Heat Flux Measurement Working Group strongly encourages the formation of commercial calibration services for routine calibration of heat flux gauges traceable to a primary method.

\section{REFERENCES}

[1] T. Ohlemiller, E. L. Johnsson, and R. G. Gann, Editors, Measurement Needs for Fire Safety: Proceedings of an International Workshop. National Institute of Standards and Technology Internal Report NISTIR 6527, Gaithersburg, MD, 270 pp, June, 2000. 
[2] W. L. Grosshandler, Heat Flux Transducer Calibration: Summary of the $2^{\text {nd }}$ Workshop. National Institute of Standards and Technology Internal Report 6424, Gaithersburg, MD, 27 pp, November, 1999.

[3] Guide for Interlaboratory Comparisons, Recommended Practice RP-15, National Conference of Standards Laboratories, March, 1999.

[4] ISO/DIS 14934-2, Fire tests - Calibration and use of heat flux meters: Part 2: Primary calibration methods, under DIS ballot.

[5] ISO/CD 14934-3, Fire tests - Calibration and use of heat flux meters: Part 3: Secondary calibration methods, under development

[6] W. M. Pitts, J. R. Lawson, and J. R. Shields, NIST/BFRL Calibration System for Heat-Flux Gages, Report of Test FR 4014, National Institute of Standards and Technology, Gaithersburg, MD, August, 2001.

[7] H. Preston-Thomas, "The International Temperature Scale of 1990 (ITS-90)," Metrologia 27, 3-10, 1990.

[8] Nordtest method NT FIRE 050, Heat flux meters: Calibration, NORDTEST, Helsinki, 1995.

[9] S. Olsson, Calibration of Radiant Heat Flux Meters - The Development of a Water Cooled Aperture for Use with Black Body Cavities, SP REPORT 1991:58, Borås, 1991.

[10] P. Andersson and I. Wetterlund, Uncertainty in Heat Flux Calibrations Performed According to NT FIRE 050, SP REPORT 2001:34, Borås, 2001. 